\title{
Injectable vaccines for preventing pneumococcal infection in patients with chronic obstructive pulmonary disease (Review)
}

\author{
Granger RH, Walters JAE, Poole P, Lasserson TJ, Mangtani P, Cates CJ, Wood-Baker R
}
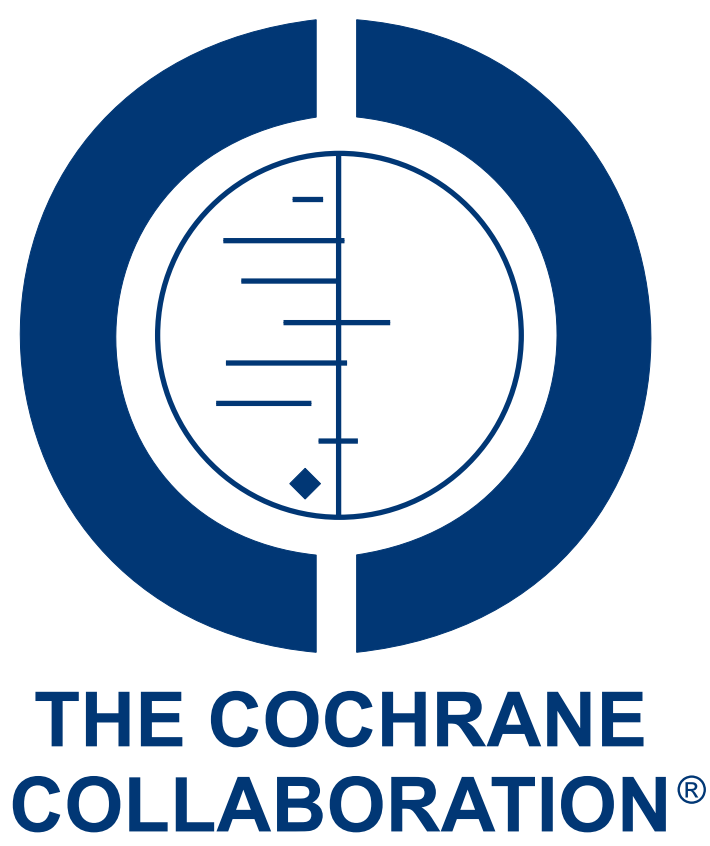

This is a reprint of a Cochrane review, prepared and maintained by The Cochrane Collaboration and published in The Cochrane Library 2006, Issue 4

http://www.thecochranelibrary.com

\section{WILEY}

Injectable vaccines for preventing pneumococcal infection in patients with chronic obstructive pulmonary disease (Review) Copyright $\odot 2009$ The Cochrane Collaboration. Published by John Wiley \& Sons, Ltd. 
TABLE OF CONTENTS

HEADER . . . . . . . . . . . . . . . . . . . . . . . . . . . . . . . . . . . . . . . . 1

ABSTRACT . . . . . . . . . . . . . . . . . . . . . . . . . . . . . . . . . . . . . . .

PLAIN LANGUAGE SUMMARY . . . . . . . . . . . . . . . . . . . . . . . . . . . . . . . . . . . 2

BACKGROUND . . . . . . . . . . . . . . . . . . . . . . . . . . . . . . . . . . . . . 2

OBJECTIVES . . . . . . . . . . . . . . . . . . . . . . . . . . . . . . . . . . . . . . . . . . . .

METHODS . . . . . . . . . . . . . . . . . . . . . . . . . . . . . . . . . . . . . .

RESULTS . . . . . . . . . . . . . . . . . . . . . . . . . . . . . . . . . . . . . . . . 4

DISCUSSION . . . . . . . . . . . . . . . . . . . . . . . . . . . . . . . . . . . . . .

AUTHORS' CONCLUSIONS . . . . . . . . . . . . . . . . . . . . . . . . . . . . . . . . . . . . . . . . . 9.9

ACKNOWLEDGEMENTS . . . . . . . . . . . . . . . . . . . . . . . . . . . . . . . . . 9

REFERENCES . . . . . . . . . . . . . . . . . . . . . . . . . . . . . . . . . . . . . . 9

CHARACTERISTICS OF STUDIES . . . . . . . . . . . . . . . . . . . . . . . . . . . . . . . . . . 13

DATA AND ANALYSES . . . . . . . . . . . . . . . . . . . . . . . . . . . . . . . . . . . . . . . . . . . . . . . . .

Analysis 1.1. Comparison 1 Pneumococcal vaccine versus control, Outcome 1 Acute exacerbations. . . . . . . . $\quad 25$

Analysis 1.2. Comparison 1 Pneumococcal vaccine versus control, Outcome 2 Pneumonia. . . . . . . . . . . . 26

Analysis 1.3. Comparison 1 Pneumococcal vaccine versus control, Outcome 3 Pneumonia by lung function at baseline. 27

Analysis 1.4. Comparison 1 Pneumococcal vaccine versus control, Outcome 4 Hospital admissions (exacerbation of COPD).

Analysis 1.5. Comparison 1 Pneumococcal vaccine versus control, Outcome 5 Patients admitted to hospital (any cause).

Analysis 1.6. Comparison 1 Pneumococcal vaccine versus control, Outcome 6 Hospital admissions (pneumonia).

Analysis 1.7. Comparison 1 Pneumococcal vaccine versus control, Outcome 7 Hospital admissions (all causes).

Analysis 1.8. Comparison 1 Pneumococcal vaccine versus control, Outcome 8 Emergency visits (upper respiratory tract infection).

Analysis 1.9. Comparison 1 Pneumococcal vaccine versus control, Outcome 9 Emergency visits (pneumonia). . . .

Analysis 1.10. Comparison 1 Pneumococcal vaccine versus control, Outcome 10 Emergency visits (lower respiratory tract infection).

Analysis 1.11. Comparison 1 Pneumococcal vaccine versus control, Outcome 11 Emergency visits (any cause). . .

Analysis 1.12. Comparison 1 Pneumococcal vaccine versus control, Outcome 12 Death from cardio-respiratory causes, 648 months post vaccine. . . . . . . . . . . . . . . . . . . . . . . . . . . . . . . . . . .

Analysis 1.13. Comparison 1 Pneumococcal vaccine versus control, Outcome 13 Death from all causes, 6-48 months post vaccine.

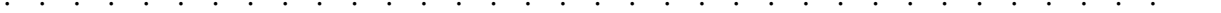

HISTORY . . . . . . . . . . . . . . . . . . . . . . . . . . . . . . . . . . . . . . .

CONTRIBUTIONS OF AUTHORS . . . . . . . . . . . . . . . . . . . . . . . . . . . . . . . . . . . . . . . . .

DECLARATIONS OF INTEREST . . . . . . . . . . . . . . . . . . . . . . . . . . . . . . . . . . . . . . . . .

SOURCES OF SUPPORT . . . . . . . . . . . . . . . . . . . . . . . . . . . . . . . . . . . . . . . . . . . . . .

INDEX TERMS . . . . . . . . . . . . . . . . . . . . . . . . . . . . . . . . . . . . 35 


\title{
[Intervention Review]
}

\section{Injectable vaccines for preventing pneumococcal infection in patients with chronic obstructive pulmonary disease}

\author{
Robert H Granger ${ }^{2}$, Julia AE Walters ${ }^{1}$, Phillippa Poole ${ }^{3}$, Toby J Lasserson ${ }^{4}$, Punam Mangtani ${ }^{5}$, Christopher J Cates ${ }^{4}$, Richard Wood- \\ Baker $^{1}$ \\ ${ }^{1}$ Menzies Research Institute, University of Tasmania, Hobart, Australia. ${ }^{2}$ Royal Hobart Hospital, Hobart, Australia. ${ }^{3}$ University of \\ Auckland, Auckland, New Zealand. ${ }^{4}$ Community Health Sciences, St George’s, University of London, London, UK. ${ }^{5}$ London School \\ of Hygiene \& Tropical Medicine, London, UK \\ Contact address: Richard Wood-Baker, Menzies Research Institute, University of Tasmania, Department of Respiratory Medicine, \\ GPO Box 1061, Hobart, Tasmania, 7001, Australia. Richard.WoodBaker@utas.edu.au.
}

Editorial group: Cochrane Airways Group.

Publication status and date: Edited (no change to conclusions), published in Issue 3, 2009.

Review content assessed as up-to-date: 20 July 2006.

Citation: Granger RH, Walters JAE, Poole P, Lasserson TJ, Mangtani P, Cates CJ, Wood-Baker R. Injectable vaccines for preventing pneumococcal infection in patients with chronic obstructive pulmonary disease. Cochrane Database of Systematic Reviews 2006, Issue 4. Art. No.: CD001390. DOI: 10.1002/14651858.CD001390.pub2.

Copyright (C) 2009 The Cochrane Collaboration. Published by John Wiley \& Sons, Ltd.

\begin{abstract}
A B S T R A C T
Background

As chronic obstructive pulmonary disease (COPD) progresses, exacerbations can occur with increasing frequency. One goal of therapy in COPD is to try and prevent these exacerbations, thereby reducing disease morbidity and associated healthcare costs. Pneumococcal vaccinations are considered to be one strategy for reducing the risk of infective exacerbations.
\end{abstract}

Objectives

To determine the safety and efficacy of pneumococcal vaccination in COPD. The primary outcome assessed was acute exacerbations. Secondary outcomes of interest included episodes of pneumonia, hospital admissions, adverse events related to treatment, disability, change in lung function, mortality, and cost effectiveness.

\section{Search strategy}

We searched the Cochrane Airways Group COPD trials register using pre-specified terms. We also conducted additional handsearches of conference abstracts. The last round of searches were performed in April 2006.

\section{Selection criteria}

Only randomised controlled trials assessing the effects of injectable pneumococcal vaccine in people with COPD were included.

\section{Data collection and analysis}

Two review authors independently extracted data and three review authors independently assessed trial quality.

\section{Main results}

Although 10 studies cited in 11 publications were identified that met the inclusion criteria for this review, only four of these provided data on participants with COPD. The studies which did provide data for this review consisted of two trials using a 14-valent vaccine, and two using a 23-valent injectable vaccine.

Injectable vaccines for preventing pneumococcal infection in patients with chronic obstructive pulmonary disease (Review)

Copyright @ 2009 The Cochrane Collaboration. Published by John Wiley \& Sons, Ltd. 
Data for the primary outcome, acute exacerbation of COPD, was available from only one of the four studies. The odds ratio of 1.43 (95\% confidence interval (CI) 0.31 to 6.69 ) between interventions was not statistically significant.

Of the secondary outcomes for which data were available and could be extracted, none reached statistical significance. Three studies provided dichotomous data for persons who developed pneumonia (OR 0.89, 95\% CI 0.58 to 1.37 , $\mathrm{n}=748$ ). Rates of hospital admissions and emergency department visits came from a single study. There was no significant reduction in the odds of all-cause mortality 1 to 48 months post-vaccination (Peto odds ratio $0.94,95 \%$ CI 0.67 to $1.33, \mathrm{n}=888$ ), or for death from cardiorespiratory causes (OR 1.07, 95\% CI 0.69 to 1.66 ).

\section{Authors' conclusions}

There is no evidence from randomised controlled trials that injectable pneumococcal vaccination in persons with COPD has a significant impact on morbidity or mortality. Further large randomised controlled trials would be needed to ascertain if the small benefits suggested by individual studies are real.

\section{PLAIN LANGUAGE SUMMARY}

\section{Injectable vaccines for preventing pneumococcal infection in patients with chronic obstructive pulmonary disease}

There is strong evidence that vaccines can protect healthy persons against infection by the pneumococcus bacteria, but little is known about the effectiveness of the vaccine in persons with chronic obstructive pulmonary disease (COPD). The results from the four randomised controlled trials included in this review with 941 participants do not show that pneumococcal vaccination provides significant protection against disease caused by the bacteria.

\section{B A C K G RO U N D}

Chronic obstructive pulmonary disease (COPD) is a common disease of older people characterised by airflow obstruction that is largely irreversible. According to World Health Organization estimates, COPD is the fourth leading cause of death worldwide resulting in more than 2.7 million deaths in 2000 (NHLBI 2001). As the disease progresses, exacerbations, some of which are infective in origin, can occur several times per year, and may require hospital admission. These exacerbations can take several weeks to resolve, and during this time cause considerable morbidity as well as leading to significant health care costs. Medicines have a limited role in the treatment of acute exacerbations and strategies that reduce exacerbation rates are therefore very appealing.

To reduce the burden of illness, pneumococcal vaccination is recommended by the major COPD guidelines (Balter 1994; NCCCC 2004), although it is not endorsed by some authorities (Chapman 1991; BTS 1997; Pauwels 2001). This recommendation appears to have been based largely on results of the efficacy of pneumococcal vaccination in observational studies in general populations, and in randomised clinical trials (RCT) in persons without COPD. Pneumococcal infection is a major cause of pneumonia, resulting in over one million deaths per year worldwide.
Streptococcus pneumoniae (pneumococcus) is one of two organisms commonly isolated from the sputum during exacerbations of COPD, the other being Haemophilus influenzae. Both a large indirect cohort study (Butler 1993) and a meta-analysis (Fine 1994) of pneumococcal vaccination have confirmed protection against invasive bacteraemic disease.

This systematic review evaluates the evidence for the efficacy of injectable pneumococcal vaccines in persons with COPD in randomised and controlled clinical trials.

\section{O B JE C T I VES}

1. To determine if pneumococcal vaccination reduces respiratory illness (acute exacerbations of COPD or pneumonia) in people with COPD.

2. To ascertain whether pneumococcal vaccination in people with COPD is associated with excess adverse events.

3. To ascertain whether pneumococcal vaccination in people with COPD reduces mortality. 
4. To ascertain whether pneumococcal vaccination in people with COPD reduces health care costs.

\section{METHODS}

\section{Criteria for considering studies for this review}

\section{Types of studies}

Only randomised controlled trials (RCT) using injectable pneumococcal vaccines were included in the review.

\section{Types of participants}

Adults with COPD defined by the American Thoracic Society (ATS 1995). This statement recognises people with a significant smoking history are at risk of developing COPD and fundamental to the diagnosis is the demonstration of airflow obstruction by lung function testing. This is demonstrated by spirometric measures; Forced expiratory volume in one second (FEV1)/Forced vital capacity (FVC) $<0.7$ and FEV $1<80 \%$ predicted.

\section{Types of interventions}

At least one injectable pneumococcal vaccination.

\section{Types of outcome measures}

The outcomes sought in the trials are divided into those of primary and secondary interest.

\section{Primary outcomes}

The number of acute exacerbations of COPD, defined as an increase in breathlessness and/or volume and/or purulence of sputum.

\section{Secondary outcomes}

1. The number of episodes of pneumonia.

2. The number of hospital admissions or visits to the emergency department.

3. Mortality in the year following vaccination. This may include mortality from respiratory disease, all causes, and causes other than respiratory disease.

4. The number of days of disability from respiratory illness variously defined as days in bed, days off work or days when the participant was unable to undertake normal activities.
5. Change in lung function.

6. Adverse effects of treatment.

7. Costs of pneumococcal vaccination (including acquisition, cost savings, health economics).

\section{Search methods for identification of studies}

We identified RCTs using the Cochrane Airways Group Specialised Register of trials which is derived from systematic searching of electronic databases including CENTRAL, MEDLINE, EMBASE and CINAHL, and handsearching of respiratory journals and meeting abstracts.

We searched all records in the Specialised Register coded as 'COPD' using the following terms:

(vaccin* or immuni*) and pneum*

An advanced search of the Cochrane Central Register of Controlled Trials (CENTRAL) was also carried out using these terms. From the full text papers obtained, we searched the bibliographic lists for additional articles.

Searches are current as of April 2006.

\section{Data collection and analysis}

We obtained the full text version of all identified articles for assessment of relevance. From the full text articles, the two review authors (PM or RG and RWB) independently established whether each study met the inclusion criteria as a RCT or CCT of pneumococcal vaccination in COPD, and that some data on one of the primary endpoints were included in the paper. The percentage agreement was recorded and disagreement was resolved by discussion between the two review authors.

It was anticipated that the follow-up period in the trials would be 12 months. If this was not the case, event rates were corrected as if they applied to a 12 month period, although this assumes that the event rate is constant over that time period.

Three review authors (RWB, RHG, JW) agreed the format of the data extraction sheets. Data was extracted by two review authors (RWB, RHG) to data extraction sheets of an agreed format, and then entered into RevMan 4.2. A third review author (JW) verified data extraction. Two review authors (RHG, JW) independently double-checked each entry.

Assessment of Study Quality

Three review authors (RWB, RHG, JW) independently assessed quality by three review authors (RWB, RHG, JW) using two methods. First, using the Cochrane approach to assessment of allocation concealment, all trials were scored and entered according to the following variables:

A: ADEQUATE if there was true randomisation i.e. a central randomisation scheme, randomisation by external person or use of coded containers/envelopes; 
B: UNCLEAR it is not possible to establish the method of allocation concealment based on the published article and/or from correspondence with the trialists;

C: INADEQUATE if there was alternate allocation, reference to case record number, date of birth, day of the week, or an open test or random numbers;

D. NOT RANDOMISED e.g. a case control or cohort study In addition, we assessed each study using a scale (scores 0 to 5) based upon the method described by Jadad (Moher 1996) and summarised as follows:

1. Was the study described as randomised $(1=$ yes; $0=$ no)?

2. Was the study described as being double blind $(1=$ yes; $0=$ no)?

3. Was there a description of withdrawals and dropouts ( $1=$ yes; $0=$ no)?

4. Was the method of randomisation well described and appropriate $(1=$ yes; $0=$ no)?

5. Was the method of double blinding well described and appropriate $(1=$ yes; $0=$ no $)$ ?

6. Deduct 1 point if methods for randomisation or blinding were inappropriate.

Inter-rater reliability was measured using simple agreement, kappa and weighted kappa statistics.

In addition it was noted, if stated in the published results, whether the study outcomes were assessed by a person who was blinded to the treatment allocation.

\section{Analysis}

Although other study designs are referred to, only data for RCTs are analysed in this review. Only dichotomous outcomes were available for analysis, and were assessed using the following statistical techniques:

- Odds ratios (OR) were calculated with 95\% confidence intervals using Peto's methods.

- Event rates are expressed as rate ratios, which is the ratio of the rate in the intervention group to the rate in the control group. The rate ratio was subsequently converted into a natural logarithm before entering into RevMan. A correction of 0.5 was added to each count where there were cells with zero events. An approximate standard error of the $\log$ rate ratio was calculated with $\sqrt{ }(1 / A+1 / C)$, where $A$ is the rate for the intervention group, and $\mathrm{C}$ is the rate for the control group.

- Funnel plots which display sample size against effect size were checked, where possible, to test for publication bias.

We carried out tests for heterogeneity during RevMan analyses. If the percentage variation not attributable to chance exceeded $30 \%$, a random-effects analysis was used to determine the impact of between study variation on the overall pooled estimate. If significant heterogeneity existed we performed sensitivity analysis using study quality as a categorising variable. If the heterogeneity was not sufficiently accounted for by study quality, we identified the following sub-group analyses a priori:

1. vaccine type;
2. severity of COPD ( assessed by lung function; mild = FEV1 50 to $79 \%$ predicted, moderate $=\mathrm{FEV} 135$ to $49 \%$ predicted and severe $=\mathrm{FEV} 1<35 \%$ predicted);

3. setting of study;

4. match between strain of vaccine and infecting strains;

5. age of patients.

\section{R E S U L T S}

\section{Description of studies}

See: Characteristics of included studies; Characteristics of excluded studies.

\section{Results of the search}

Searches conducted in 2003 of the Airways Group COPD trials register yielded a total of 46 references. However, additional hand searching of conference proceedings and bibliographies of published articles identified a further 27 references that were subsequently retrieved. Of the 73 articles, 65 did not meet the inclusion criteria (review article: $\mathrm{N}=25$; cohort or case controlled study: $\mathrm{N}$ = 12; inappropriate patient population: $\mathrm{N}=3$; participants unlikely to have had COPD: $\mathrm{N}=6$; retrospective studies of efficacy or isolates: $\mathrm{N}=3$; cost benefit or effectiveness analysis: $\mathrm{N}=3$; study of antibody response: $\mathrm{N}=2$; position paper: $\mathrm{N}=1$; editorial: $\mathrm{N}=1$; inappropriate comparison: $\mathrm{N}=1$; inappropriate randomisation: $\mathrm{N}=1$; meta-analysis: $\mathrm{N}=1$; trial of immunization rates: $\mathrm{N}=1$; case report: $\mathrm{N}=1$; survey: $\mathrm{N}=1$; duplicate publication: $\mathrm{N}=1$; correspondence: $\mathrm{N}=1$; commentary: $\mathrm{N}=1$ ); six contained participants with COPD for which no data were available for this sub-group, and two trials met all criteria and for which data could be extracted for this review. A further search of the Airways Group trials register in April 2004 yielded an additional 16 citations of which 15 failed to meet the inclusion criteria (totally irrelevant: $\mathrm{N}$ $=8$; inappropriate intervention: $\mathrm{N}=2$; inappropriate (oral) vaccination: $\mathrm{N}=2$; study of antibody response: $\mathrm{N}=1$; inappropriate comparison: $\mathrm{N}=1$; commentary: $\mathrm{N}=1$ ). A further search in 2006 produced one further publication of interest.

For full details of exclusions, see Characteristics of excluded studies.

\section{Included studies}

For specific details of each study included in the review, see Characteristics of included studies.

Two studies required translation into English based upon a standardised translation pro forma used by the Airways Group: Gaillat 1985 from French, and the pre-published report of Alfageme 2006 from Spanish. 
Of the 10 studies identified that included participants with chronic lung disease (in 11 citations; Davis 1984 briefly cites preliminary results of the study published later in Davis 1987), only four studies could be included in the analyses. The four randomised controlled trials of pneumococcal vaccines included a total of 937 participants with outcome data for COPD participants (Alfageme 2006; Davis 1987; Leech 1987; Steentoft 2006). Two of these studies used 23-valent pneumococcal vaccines (Alfageme 2006; Steentoft 2006) while the other two studies used 14-valent pneumococcal vaccines (Davis 1987; Leech 1987). Three of the four trials were placebo-controlled, while the participants in Alfageme 2006 were randomised to receive either vaccination or no vaccination and thus by definition was only single-blind.

The six trials that included persons with chronic lung diseases for which outcome data were unavailable are Gaillat 1985, Klastersky 1986, Koivula 1997, Ortqvist 1998, Riley 1977 and Simberkoff 1986. All authors responded to our requests for sub-group analyses for COPD participants, though none were able to provide data. The six studies were conducted in mainly elderly and/or chronically ill participants of whom a proportion had chronic lung disease. Riley 1977 included 11,958 participants in the highlands of Papua New Guinea, some of which had "chronic lung disease". The proportion of persons with lung disease is not stated. Gaillat 1985 reports results on 1,686 persons living in aged care facilities in France. The author indicated that it was highly likely that persons with COPD were among the studied participants, though no analyses are available for this subgroup. The proportion of persons with lung disease is not stated. The study by Klastersky 1986 was conducted in 50 persons with bronchogenic carcinoma. The author mentioned that many of these persons had COPD, though the original analyses did not stratify by this group. Simberkoff 1986 studied 2,295 high risk individuals from north-eastern USA, and which included persons with chronic pulmonary diseases $(23.4 \%$ of all participants). The single-blinded study by Koivula 1997 was conducted in 2,837 elderly participants living in Sweden, and included participants with "lung disease" (4.5\% of all participants). The trial by Ortqvist 1998 studied 691 non-immunocompromised participants aged 50 to 85 years from Sweden, of whom $21.7 \%$ had self-reported chronic pulmonary disease.

It is worthwhile noting why one particular study (Halasa 2001, written in the Polish language) was not included in this review. It is a double blind, placebo controlled trial with 24 patients who had non-atopic infectious asthma and COPD. Phase 1 of the trial was a parallel study, with phase 2 being a cross-over study. Although the placebo used a saline injection, the reason for exclusion was that the intervention used an injectable auto vaccine prepared from pathogenic and physiological bacterial strains. The study protocols strictly limited the injectable vaccine to a standardised dose of either 14- or 23-valent pneumococcal antigen.

The following descriptions refer only to the four studies which met the inclusion criteria for this review. Further details are available in the table for 'Characteristics of included studies'.

\section{Study setting and design}

All studies were conducted in a community setting.

All four studies were randomised, parallel group trials. Davis 1987 allocated participants to treatment groups using random number tables. Steentoft 2006 used block randomisation to assign participants to either one of three treatment groups or to the control group, and is not described as a double-blind study. Alfageme 2006 assigned participants in blocks of 10 per group by means of a random number generator. Leech 1987 does not describe the randomisation methods. Blinding was briefly described for Davis 1987, Leech 1987, and Steentoft 2006 clearly describes its method of allocation concealment.

\section{Patient population}

The common inclusion criterion for each of the four studies was for participants to have COPD, and the common exclusion criteria was previous pneumococcal vaccination. Davis 1987 included 103 COPD participants with disease status determined by clinical and pulmonary function criteria (not further defined). The average FEV1 in the active group was $1.33 \mathrm{~L}$. Participants were followed for 24 to 32 months. Leech 1987 recruited 189 participants with COPD $($ FEV1 < $1.5 \mathrm{~L})$ diagnosed by a physician. The average FEV1 for the active group was $0.94 \mathrm{~L}$. Participants were followed for a total of two years. The subjective nature of the diagnoses made in both of these studies, together with the absence of reversibility testing, does not exclude the possibility that study samples were contaminated with asthmatic participants. For details of lung function parameters at baseline in both studies please see "Characteristics of included studies". Alfageme 2006 recruited 600 participants with a loss of four to follow up. Of those in the active group, $44 \%$ of experimental participants had an FEV1 < $40 \%$ expected (38\% in the control group). Thirty females were included in the study. The study by Steentoft 2006 included a total of 49 participants ( 27 male) and was primarily aimed at assessing the efficacy of pneumococcal vaccination with a co-intervention of steroid treatment. Participants were assigned to one of three intervention groups that differed according to the timing, duration and dose of systemic steroid treatment. The control group was not given a vaccine, and it is assumed that it also did not receive any steroid treatment. COPD was diagnosed according to GOLD criteria.

Age: The average age of participants was similar in all studies (mid to high 60's).

Tobacco smoking status: Davis 1987 describes 53\% as current smokers in the vaccine group versus $33 \%$ in placebo, with five never smokers in each group. In Alfageme 2006, there were 65 current smokers in the vaccine group and 77 in the control group. Steentoft 2006 describes $46 \%$ of the participants in the intervention groups $(\mathrm{n}=37)$ and $58 \%$ of the controls $(\mathrm{n}=12)$ as being current smokers with the rest being previous smokers. 
Co morbidities: Davis 1987 indicates that the number of patients were similar in both groups for cardiovascular disease, diabetes, and history of excessive alcohol consumption. Alfageme 2006 shows no difference between groups in terms of previous pneumonia or tuberculosis. There was also no between-group difference in detection of neoplasia during follow-up. Steentoft 2006 and Leech 1987 do not report comorbid conditions.

Drop-outs: For Leech 1987, 23 persons in total were lost to follow up (group allocation not reported); Alfageme 2006, two persons from each group lost to follow up; dropouts in Davis 1987 and Steentoft 2006 were not explicitly stated, giving the appearance that there were none.

\section{Intervention}

Davis 1987 and Leech 1987 used injectable vaccines of 14-valent pneumococcal capsular antigens in the active groups, with sterile physiologic saline placebo for the control groups. Davis 1987 injected a standard dose of the 14 valent pneumococcal capsular antigens $(0.5 \mathrm{ml}$ containing $50 \mathrm{mcg}$ of each of the 14 capsular antigens, totaling $700 \mathrm{mcg}$ ). The dose was not stated for Leech 1987 , though it is assumed to be the same as that given in Davis 1987. Steentoft 2006 and Alfageme 2006 used $0.5 \mathrm{ml}$ of 23-valent pneumococcal vaccines for the treatment groups (containing 25 mcg of each antigen totaling $575 \mathrm{mcg}$ ). In both of these studies, the vaccine was withheld from the control groups instead of the administration of a placebo and are therefore single-blind studies by definition. Injections in all studies were given subcutaneously. Participants were followed up for 48 months post-vaccination in Davis 1987 , 24 months in Leech 1987 and six months for Steentoft 2006. The median study duration for Alfageme 2006 was approximately 980 days.

\section{Outcomes}

Available outcome data are summarised in the 'Additional Tables'. All studies except Steentoft 2006 provided mortality data. The incidence of pneumonia was available from Davis 1987, Alfageme 2006, and Steentoft 2006. In addition, Davis 1987 and Leech 1987 measured antibody titers. As this review is concerned with clinical rather than biological outcomes, these data were not extracted. Leech 1987 also recorded emergency visits, admission to hospital, length of hospital stay and adverse events. No data are available for length of stay and adverse events.

\section{Risk of bias in included studies}

For the four studies in the review, quality was assessed using two methods:

\section{Adequacy of concealment}

Based on the published articles, it was possible to establish the method of allocation concealment for only one of the four studies (Steentoft 2006). This study was given an A grade while the reaminating studies received a $\mathrm{B}$. The trialists were not contacted for more details on this particular issue.

\section{Jadad Score}

One study had a score of 4/5 (Davis 1987), two studies 3/5 (Leech 1987, Alfageme 2006) and one with a score of 2/5 (Steentoft 2006).

\section{Effects of interventions}

After extensive electronic and handsearching, we located 11 citations (reporting 10 studies) that met the inclusion criteria. Of these 10 studies, only four were conducted on participants where COPD was an inclusion criterion for study participation. In these four studies, there was a total of 937 case-available participants. The other six papers reported trials of elderly and /or chronically ill patients of whom a subset had chronic lung disease, but for which no data was available to include in this review. With one exception, data is displayed in the tables of comparisons by the number of capsular polysaccharide antigens used in the vaccine (greater than 14 versus 14 or less). The exception is for the pneumonia outcome, where provision is made for stratifying results according to baseline lung function. No data was available for 4 of the 8 proposed outcomes: days of disability; change in lung function; adverse effects of treatment; and cost of pneumococcal vaccination.

Only dichotomous data are reported, as no continuous data for the outcomes of interest were available. The generic inverse variance methodology was used for determining rate ratios for intervention and control groups for two outcomes (hospital admissions and emergency department visits). Ninety five percent confidence intervals (95\% CI) were applied to fixed odds ratios (OR) and fixed rate ratios (RR). No meta-analyses included data that were derived from all four studies.

\section{Primary outcome}

\section{Acute exacerbations}

Only Steentoft 2006 provided data for participants who experienced acute exacerbations of COPD. There was no significant difference between vaccination and placebo for this outcome, OR 1.43 (95\% CI 0.31 to 6.69). Leech 1987 provided hospital admission rates due to acute exacerbations (rate ratio 0.83 ), but this also found no significant difference between interventions. 


\section{Secondary outcomes}

\section{Pneumonia}

Davis 1987, Alfageme 2006, and Steentoft 2006 reported data for participants suffering one or more episodes of pneumonia. Overall, there was no significant difference between intervention and control groups, odds ratio 0.89 (95\% CI 0.58 to 1.37 ). Only Alfageme 2006 reported results by COPD severity: vaccinated persons with FEV1 < 40\% predicted at baseline had an odds of contracting pneumonia of 0.47 (95\% CI 0.22 to 1.01 ) compared to control participants, whereas vaccinated participants with a FEV1 $\geq 40 \%$ predicted had an odds ratio of 1.12 (95\% CI 0.5 to 2.49 ) compared to control. Leech 1987 provided rates of hospital admissions and emergency visits due to pneumonia (rate ratio 1.98 and 0.99 respectively, neither reaching statistical significance).

\section{Hospital admissions}

Leech 1987 and Steentoft 2006 reported details of hospitalisation, but it was not possible to combine the data in a meta-analysis. Leech 1987 reported rates of hospital admissions for pneumonia (rate ratio $1.98,95 \% \mathrm{CI} 0.66$ to 5.91 ), for acute exacerbations (rate ratio $0.83,95 \%$ CI 0.54 to 1.27 ), and for all causes (rate ratio $1.01,95 \%$ CI 0.72 to 1.41 ), none of which were significantly different between intervention and control groups. Steentoft 2006 reported the actual numbers of participants admitted to hospital for the three intervention and single control groups. Once again no significant difference was found between interventions (OR $0.95,95 \%$ CI 0.26 to 3.48 ).

\section{Emergency department visits}

Only Leech 1987 reported results for emergency department visits. As for hospital admissions, no significant difference between vaccination and control groups was found for emergency visits due to pneumonia (rate ratio 0.99 ; $95 \%$ CI 0.52 to 1.88 ), lower respiratory tract infections (rate ratio $1.00,95 \% \mathrm{CI} 0.75$ to 1.33 ), or upper respiratory tract infection (rate ratio 1.29 , 95\% CI 0.68 to 2.47). There was no significant difference between interventions for all-cause visits to the emergency department, rate ratio 1.15 (95\% CI 0.68 to 2.47 ).

\section{Mortality}

Three studies (Davis 1987; Leech 1987; Alfageme 2006) that included 888 participants provided data for death from all causes. There was no significant difference between interventions for all cause mortality, OR 0.94 (95\% CI 0.67 to 1.33 ), or death from cardiorespiratory causes, OR 1.07 (95\% CI 0.69 to 1.66 ).

With respect to mortality, the follow-up period for each of these three studies differed. Davis and Alfageme followed participants up to 48 months, while Leech followed participants for 24 months. None reported mortality statistics for the first 12 months only.

\section{Other secondary outcomes}

None of the studies reported data for disability, change in lung function, adverse effects nor costs associated with pneumococcal vaccination. However, Leech stated "There were no adverse reactions to pneumococcal vaccine" and Alfageme indicated that "no patient reported any local or systemic reaction to the vaccine". Davis 1987 and Steentoft 2006 do not make any specific reference to adverse effects, although Davis states that participants had a "normal response to the vaccine", which is believed to refer to antibody responses.

\section{I S C USSION}

In this systematic review, we have included four RCTs which report the effects of injectable pneumococcal vaccination in persons with COPD. There were no statistically significant findings from this review to indicate whether pneumococcal vaccination provides protection against acute exacerbations or pneumonia in persons with COPD.

Unfortunately the outcomes reported in the studies allowed few to be combined in any of the meta-analyses we performed. Rates of hospital admissions and emergency department visits were derived from only one study (Leech 1987). The methodological quality of this study involving 189 participants was acceptable, but failed to show any difference in rates between the two interventions. The inability to detect a difference may have been due to a combination of small sample size, and a low frequency of pneumococcal infection. The authors performed a power calculation which suggested that at least 500 participants in each group would have been required to show a statistically-significant risk reduction of $40 \%$ for pneumococcal infection. In addition, the authors also suggest that the low infection rates in this population may have been due to naturally-acquired antibodies from prior infections, effectively diminishing the apparent efficacy of the vaccine.

Davis 1987 also had a small number of participants with COPD in the trial $(n=103)$. Of interest is the prevalence of pre-vaccination isolation of pneumococcus from sputum (active $=9 \%$; placebo $=13 \%$ ) compared to post-vaccination isolation (active $=13 \%$; placebo $=7 \%$ ). The placebo group in this study had an estimated post-intervention rate of pneumonia of 49/1000 pt-yrs, versus $30.3 / 1000 \mathrm{pt}-\mathrm{yrs}$ in the active group. Interpretation of these results is confounded by the difference between the two groups for rates of pneumococcal pneumonia prior to the study (placebo $=22.9$ / $1000 \mathrm{pt}$-yrs, active 13.8/1000 pt-yrs) and any pneumonia (placebo $=57 / 1000$ pt-yrs, active 35/1000 pt-yrs). 
The largest study is by Alfageme 2006, though it does not appear to have the same methodological rigour as that of the others. The study was initially identified in a hand-search of abstracts from conference proceedings, with preliminary results obtained from direct contact with the authors. The full results of the study were formally published in 2006. It could be argued that since the single-blind study design failed to include a placebo comparison, it is inappropriate for inclusion in this review. It is nonetheless a randomised trial where one group of patients were allocated to receive the 23-valent vaccine, and the other (control) group allocated to receive no intervention. Even with the limitations inherent with this study design, the results are in keeping with the other trials of injectable vaccines. If gender is thought to modify the biological activity of the vaccine, the generalisability of the results may be limited since only $5 \%$ of the participants were female. As cigarette smoking is widely recognized as the single biggest risk factor in the development of COPD, the imbalance of gender in this study may simply be a reflection of the imbalance of male and female smokers in the country where the study was conducted (Spain). Across all studies, there were insufficient data to stratify results by gender.

Steentoft 2006 was the smallest of the four studies ( $\mathrm{n}=49$ ), and interpretation of the results are complicated by the fact that there was a co-intervention requiring participants to be placed into one of three steroid treatment groups $(n=13,9,15)$ or a control group. It appears that the researchers in this study were particularly interested, as were those in Leech 1987 and Davis 1987, in biological outcomes such as antibody levels.

Disappointingly, analysis by severity of COPD was possible for only one study (Alfageme 2006). In addition, no studies provided data for side effects of the vaccination under investigation, other than stating that the vaccines were well tolerated.

There were a further six RCTs that could have contributed data for this review if sub-group analyses had been available for the participants with COPD. In the study by Klastersky 1986, all participants were admitted with bronchogenic carcinoma and it is likely some of these would have had coexistent COPD. Most other studies excluded persons with malignancies. There were no differences in clinical outcomes $(11.5 \%$ in the vaccine group versus $19 \%$ in the placebo developed pneumococcal infections) between the interventions. The study by Gaillat 1985 undertaken among residents living in aged-care facilities favoured vaccination with respect to pneumonia, though there was no reduction in risk of mortality. In the single-blind study of elderly participants by Koivula 1997, the overall results showed no reduction in events of pneumonia between interventions. A sub-group analysis showed a protective effect of pneumococcal vaccination in those persons at increased risk of pneumonia (age $\geq 70$ years, heart disease, lung disease, bronchial asthma, alcoholism, institutionalised, or permanently bedridden). The protective efficacy, defined as 100 $\mathrm{x}$ (1-odds ratio of having been vaccinated), was 59\% (95\% CI 6 to $82 \%)$ in this increased risk sub-group This finding is not in keeping with that of Simberkoff 1986, who conducted a study in 2295 high-risk patients aged $>50$ years and found no difference in events of pneumonia or bronchitis. Persons at high risk of pneumonia in this population were defined by having one or more of the following risk factors: age $>55$, chronic renal, hepatic, cardiac or pulmonary diseases, alcoholism, or diabetes mellitus. The study by Riley 1977 in 11,958 persons in the highlands of Papua New Guinea showed a reduction in deaths from respiratory causes, though the vaccine had little efficacy in protecting against lower respiratory tract infections. The trial by Ortqvist 1998 in persons aged 50 to 85 years was unable to show a reduction in risk of pneumonia, pneumococcal pneumonia, and mortality for the vaccine group compared to those receiving a saline placebo.

Studies using a retrospective, case-control design have found that pneumococcal vaccination has an efficacy of approximately 50 to $80 \%$ against invasive pneumococcal disease in high risk populations (Fedson 1994; Leophonte 2001). The data derived from such studies often included persons with chronic lung conditions, though analyses were not limited to persons with only COPD. Prospective cohort studies have generally failed to show reductions in the risk of non-bacteraemic infections, though protection against bacteraemia has been demonstrated (Jackson 2003). An indirect cohort study conducted by the Centers for Disease Control and Prevention documented an efficacy of 65\% (95\% CI $26 \%$ to $83 \%$ ) in persons with chronic pulmonary diseases (Butler 1993). This study utilised cases of pneumococcal infection, and compared the distribution of pneumococcal serotypes causing infection in those who were vaccinated and unvaccinated. Regardless of design, most studies have found that the protective efficacy of vaccination is uniformly diminished in the elderly and immunocompromised.

Pneumococcal vaccination in COPD is generally advocated in clinical guidelines by the internationally-recognised thoracic societies. The American Thoracic Society together with the European Respiratory Society released guidelines in June 2004, stating that "vaccination against pneumococcal disease reduces bacteraemia in vaccinated patients with pneumonia. The vaccination is indicated for all elderly patients depending on national recommendations" (ATS 2004). Guidelines from the UK's National Institute of Clinical Excellence (NICE) state that "pneumococcal vaccination and an annual influenza vaccination should be offered to all patients with COPD as recommended by the Chief Medical Officer" (NICE 2004). The COPDX guidelines for Australia and New Zealand state that "pneumococcal vaccination (polyvalent covering 23 virulent serotypes) is recommended in this group. The vaccination should be repeated five-yearly. There is no evidence or rationale for vaccinating more frequently in COPD" (McKenzie 2003). There is less enthusiasm for such a recommendation by the Global Initiative for Chronic Obstructive Lung Disease (GOLD) guidelines published jointly by the USA's National Heart Lung 
Blood Institute and the World Health Organization. This guideline suggests that "pneumococcal vaccine containing 23 virulent serotypes has been used but sufficient data to support its general use in COPD patients are lacking” (NHLBI 2001). Our findings from the available RCT evidence is that injectable polyvalent vaccines have not been shown to provide significant protection against morbidity and mortality in persons with COPD.

\section{Methodological limitations}

The total number of participants that contributed data to this review was 937 participants. Given the small number of trials and few participants, it is not possible to exclude the possibility that vaccination is efficacious for the outcomes investigated. As Fedson et al indicate in their commentary (Fedson 1994), it is possible that one reason clinical trials have failed to show a benefit from pneumococcal vaccination is an overestimation of the incidence of pneumococcal infections in the study population, rather than a lack of vaccine efficacy per se. Another possibility is the small participant numbers for most outcomes; as Leech 1987 suggested, participant numbers close to 1000 would be needed to demonstrate whether some findings from individual studies are indeed statistically significant. We were able to include numbers of this magnitude for a minority of our outcomes.

\section{A U THORS'CONCLUSIONS}

\section{Implications for practice}

The limited evidence from RCTs included in this review of persons with COPD found no significant difference for morbidity or mortality between those injected with pneumococcal vaccination and those who served as controls.

\section{Implications for research}

The evidence of efficacy for pneumococcal vaccination in COPD is derived from RCT level evidence, which is conflicting. Such evidence is limited by few randomized trials, small sample size, utilisation of post hoc or sub-group analyses, and inconsistent results. The recommendations in clinical practice guidelines may have been based largely on evidence in participants different to the target population (persons with COPD). What is needed to confirm efficacy of pneumococcal vaccination in COPD are large, adequately powered randomised placebo-controlled trials using participants with COPD.

\section{ACKNOW LEDGEMENTS}

We acknowledge the support of the Cochrane Airways Group.

\section{R E F E R E N C E S}

\section{References to studies included in this review}

Alfageme 2006 \{published data only\}

Alfageme I, Reyes N, Vazquez R, Perez J, Munoz, Hernandez $\mathrm{M}$, et al.Clinical efficacy of pneumococcal vaccine in COPD patients. Preliminary results. Chest 2004;126(4 Suppl): 837S.

* Alfageme I, Vazquez R, Reyes N, Munoz J, Fernandez A, Hernandez M, et al.Clinical efficacy of anti-pneumococcal vaccination in patients with COPD. Thorax 2006;61: 189-95.

Davis 1987 \{published data only\}

Davis AL, Aranda CP, Schiffman G, Christianson LC. [Pneumoccoccal infection and immunologic response to pneumococcal vaccine in chronic obstructive pulmonary desease. A pilot study]. Chest 1987;92(2):204-12.

Leech 1987 \{published data only\}

Leech JA, Gervais A, Ruben FL. Efficacy of pneumococcal vaccine in severe chronic obstructive pulmonary disease. CMAJ 1987;136(4):361-5.

Steentoft 2006 \{published data only\}

* Steentoft J, Konradsen HB, Hilskov J, Giglason G, Andersen JR. Response to pneumococcal vaccine in chronic obstructive lung disease - the effect of ongoing, systemic steroid treatment. Vaccine 2006;24:1408-12.

\section{References to studies excluded from this review}

Aboussouan 1996 \{published data only\}

Aboussouan LS. Acute exacerbations of chronic bronchitis: Focusing management for optimum results. Postgraduate Medicine 1996;99(4):89-104.

Anonymous 1999 \{published data only\}

Anonymous. Pneumococcal vaccines: World Health Organization position paper. Weekly Epidemiological Record 1999;74(23):177-83.

Anonymous 1999b \{published data only\} Anonymous. Pneumococcal vaccines: World Health Organization position paper. Canada Communicable Disease Report 1999;25(17):150-1.

Austrian 1976 \{published data only\} Austrian R, Douglas RM, Schiffman C. Prevention of pneumococcal pneumonia by vaccination. Transactions of the Association of American Physicians 1976;89:184-94.

Austrian 1981 \{published data only\}

Austrian R. Some observations on the pneumococcus and on the current status of pneumococcal disease and its prevention. Reviews of Infectious Diseases 1981;3(Suppl): S1-S17. 
Austrian 1984 \{published data only\}

Austrian R. A reassessment of pneumococcal vaccine. New England Journal of Medicine 1984;310:651-3.

Bacle 1997 \{published data only\}

Bacle A, Diot P, Lemarie E. Anti-pneumococci vaccine: justifications and results. Revue de Pneumologie Clinique 1997;53(3):128-37.

Bentley 1981 \{published data only\}

Bentley DW. Pneumococcal vaccine in the institutionalized elderly: review of past and recent studies. Reviews of Infectious Diseases 1981;3(Suppl):S61-S70.

Bolan 1986 \{published data only\} Bolan G, Broome CV, Facklam RR, Plikaytis BD, Fraser DW, Schlech WF. Pneumococcal vaccine efficacy in selected populations in the United States. Annals of Internal Medicine 1986;104:1-6.

Broome 1981 \{published data only\} Broome CV. Efficacy of pneumoncoccal polysaccharide vaccines. Reviews of Infectious Diseases 1981;3(Suppl): S82-S88.

Butler 1992 \{published data only\} Butler JC, Breiman RF, Campbell JF, et al.Efficacy of the pneumoncoccal vaccine: Is once enough?. Interscience Conference of Antimicrobial Agents and Chemotherapy, Anaheim, CA. 1992.

Butler 1993 \{published data only\} Butler JC, Breiman RF, Campbell JF, Lipman HB, Broome C, Facklam RR. Pneumococcal polysaccharide vaccine efficacy. JAMA 1993;270:1826-31.

Chodosh 1991 \{published data only\} Chodosh S. Treatment of acute exacerbations of chronic bronchitis: state of the art. The American Journal of Medicine 1991;91(Suppl 6A):87S-91S.

Christenson 2001 \{published data only\} Christenson B, Lundbergh P, Hedlund J, Ortqvist A. [Effects of a large-scale intervention with influenza and 23 -valent pneumococcal vaccines in adults aged 65 years of older: a prospective study]. Lancet 2001;357(9261): 1008-11.

Davis 1984 \{published data only\}

* Davies AL. Effects of 14-valent pneumococcal polysaccharide vaccine in patients with COPD. Chest 1984; 85(Suppl):582-3.

Douglas 1979 \{published data only\}

Douglas RM, Riley ID. Pneumococcal disease and its prevention with plyvalent pneumococcal polysaccharide vaccines- a review. Australian and New Zealand Journal of Medicine 1979;9(327-38).

Douglas 1984 \{published data only\}

Douglas RM, Miles HB. Vaccination against streptococcus pneumoniae in childhood: lack of demonstrable benefit in young Australian children. The Journal of Infectious Diseases 1984;149(6):861-9.
Ekwurzel 1938 \{published data only\}

Ekwurzel GM, Simmons JS, Dublin LI, Felton LD. Studies on immunizing substances in pneumococci. Public Health Reports 1938;53:1877-93.

Ewig 1999 \{published data only\}

Ewig S, Soler N, Torres A. Chronic obstructive pulmonary disease and infection: from stable patients to pneumonia. Clinical Pulmonary Medicine 1999;6(1):1-8.

Farr 1995 \{published data only\}

Farr BM, Johnston BL, Cobb DK, et al.Preventing pneumoncoccal bacteremia in patients at risk. Archives of Internal Medicine 1995;155:2336-40.

Fedson 1989 \{published data only\} Fedson D, Henrichsen J, Makela H, Austrian R. Immunization of elderly people with polyvalent pneumococcal vaccine. Infection 1989;617(6):437-41.

Fedson 1994 \{published data only\}

Fedson DS, Shapiro ED, LaForce FM, Mufson MA, Musher DM, Spika JS, et al.Pneumococcal vaccine after 15 years of use. Another view. Archives of Internal Medicine 1994;154 (22):2531-5.

Fedson 1999 \{published data only\} Fedson DS. The clinical effectiveness of pneumococcal vaccination: a brief review. Vaccine 1999;17:S85-S90.

Felton 1938 \{published data only\}

Felton LD, Ekwurtzel GM, Simmons JS, Dublin LI. Public Health Reports 1938;53:1877.

Ferguson 1993 \{published data only\} Ferguson GT, Cherniack RM. Management of chronic obstructive pulmonary disease. New England Journal of Medicine 1993;328(17):1017-22.

Filice 1990 \{published data only\} Filice GA. Pneumoccal vaccines and public health policy. Archives of Internal Medicine 1990;150:1373-5.

Fine 1994 \{published data only\} Fine MJ, Smith MA, Carson CA, Meffe F, Snakey SS, Weissfeld LA, et al.Efficacy of pneumococcal vaccination in adults. A meta-analysis of randomized controlled trials. Archives of Internal Medicine 1994;154(23):2666-77.

Forrester 1987 \{published data only\} Forrester HL, Jahnigen DW, LaForce FM. Inefficacy of pneumococcal vaccine in a high-risk population. The American Journal of Medicine 1987;83(3):425-30.

Foschino 1995 \{published data only\} Foschino BMP, Resta O, Cassano A, Altieri A, Guido P, Piti A, et al.Infectious exacerbations of chronic pulmonary diseases. Therapeutic effectiveness of immunomodulants [Riacutizzazioni delle broncopneumopatie croniche]. Minerva Pneumologica 1995;43(2):39-44.

Gable 1990 \{published data only\} Gable CB, Holzer SS, Engelhart L, Friedman RB, Smeltz F, Schroeder D, et al.Pneumococcal vaccine: efficacy and associated cost savings. JAMA 1990;264:2910-5. 
Gaillat 1985 \{published data only\}

Gaillat J, Zmirou D, Mallaret MR, et al.Clinical trial of an antipneumococcal vaccine in elderly subjects living in institutions [Essai clinique du vaccin antipneumococcique chez des personnes agees vivant en institution]. Revue d'Epidemiologie et de Sante Publique 1985;33(6):437-44.

Gardner 1993 \{published data only\} Gardner P, Schaffner W. Immunization of adults. New England Journal of Medicine 1993;328(17):1252-8.

Hak 1998 \{published data only\}

Hak E, van Essen GA, Buskens E, Stalman W, de Melker RA. Is immunising all patients with chronic lung desease in the community against influenza cost effective? Evidence from a general practice gased clinical prospective cohort study in Utrecht, The Netherlands. Journal of Epidemiology and Community Health 1998;52(2):120-5.

Halasa 2001 \{published data only\}

Halasa J, Halasa M, Wojciechowska W, Podkowinska I, Kucharska E. Clinical efficacy of autovaccine in the treatment of infectious nonatopic asthma and COPD - double blind placebo controlled trial [Ocena efektow leczenia autoszczepionka astmy nieatopowej infekcyjnej i POChP - badanie z zastosowaniem podwojnie slepej proby z placebo]. Alergia Astma Immunologia 2001;6(2):109-13.

Hilleman 1981 \{published data only\} Hilleman MR, Carlson AJJr, McLean AA, Vella PP, Weibel RE, Woodhour AF. Streptococcus pneumoniae polysaccharide vaccine: age and dose responses, safety, persistence of antibody, revaccination, and simultaneous administration of pneumococcal and influenza vaccines. Reviews of Infectious Diseases 1981;3(Suppl):S31-S42.

Hirschmann 1981 \{published data only\} Hirschmann JV, Lipsky BA. Pneumococcal vaccine in the United States: a critical analysis. JAMA 1981;246:1428-32.

Hirschmann 1994 \{published data only\} Hirschmann JF. The pneumococcal vaccine after 15 years of use. Archives of Internal Medicine 1994;154:373-7.

Horwood 2002 \{published data only\}

* Horwood F, Macfarlane J. Pneumococcal and influenza vaccination: current situation and future prospects. Thorax 2002;57(Suppl II):ii24-ii30.

Jackson 2003 \{published data only\} * Jackson L, Neuzil K, Yu O, Benson P, Barlow W, Adams A, et al.Effectiveness of pneumococcal polysaccharide vaccine in older adults. New England Journal of Medicine 2003;348 (18):1747-55.

Jonsson 2002 \{published data only\} Jonsson S, Vidarsson G, Valdimarsson H, Schiffman G, Schneerson R, Jonsdottir I. Vaccination of COPD patients with a pneumococcus type $6 \mathrm{~B}$ tetanus toxoid conjugate vaccine. European Respiratory Journal 2002;20(4):813-8.

Kaiser 1974 \{published data only\}

Kaiser AB, Schaffner W. Prospectus: the prevention of bacteremic pneumococcal pneumonia. A conservative appraisal of vaccine intervention. Journal of the American Medical Association 1974;230(3):404-8.

Kaufman 1941 \{published data only\}

* Kaufman P. Studies on old age pneumonia II. Prophylactic effect of pneumoncoccus polysaccharide against pneumonia. Archives of Internal Medicine 1941;67:304-19.

Kaufman 1947 \{published data only\}

Kaufman P, Kaeffely A, Klingst SK, O'Brien C, Stein $\mathrm{H}$. Pneumonia in old age: active immunization against pneumonia with pneumococcus polysaccharide: results of a six-year study. Archives of Internal Medicine 1947;79: 518-31.

Klastersky 1986 \{published data only\} Klastersky J, Mommen P, Cantraine F, Safary A. Placebo controlled pneumococcal immunisation in patients with bronchogenic carcinoma. European Journal of Cancer and Clinical Oncology 1986;22:807-13.

\section{Klein 1983 \{published data only\}}

Klein RS, Adachi N. Pneumococcal vaccine in the hospital. Improved use and implications for high-risk patients. Archives of Internal Medicine 1983;143(10):1878-81.

Koivula 1997 \{published data only\}

Koivula I, Sten M, Leinonen M, Makela PH. Clinical efficacy of pneumococal vaccine in the elderly: A randomized, single-blind population-based trial. American Journal of Medine 1997;103:281-90.

Kraus 1985 \{published data only\}

* Kraus C, Fischer S, Ansorg R, Huttemann U. Pneumococcal antibodies (IgG, IgM) in patients wih chronic obstructive lung disease 3 years after pneumococcal vaccination. Medical Microbiology and Immunology 1985; 174(1):51-8.

LaForce 1989 \{published data only\} LaForce LM. Pneumococcal vaccine. Seminars in Respiratory Infections 1989;4(4):293-8.

Landesman 1983 \{published data only\} Landesman SH, Smith PM, Schiffman G. Pneumococcal vaccine in elderly patients with COPD. Chest 1983;84: 433-5.

Larsson 1998 \{published data only\} Larsson L. Use of antibiotics, antioxidants, mucolytics and vaccines in the therapy of chronic obstructive pulmonary disease. European Respiratory Monograph 1998;3(7):163-8.

Leophonte 2001 \{published data only\} Leophonte P, Neukirch F. Anti-pneuococci vaccination: Role and indications in the prevention of community acquired infections of the lower respiratory tract. Medecine et Maladies Infectieuses 2001;31(4):181-94.

MacLeod 1945 \{published data only\} MacLeod CM, Hodges RG, Heidelberger M, Bern Hard NG. Prevention of pneumococcal pneumonia by immunisation with specific capsular polysaccharide. The Journal of Experimental Medicine 1945;82:445-65. 
Madison 1998 \{published data only\}

Madison JM, Irwin RS. Chronic obstructive pulmonary

disease. Lancet 1998;352(9126):467-73.

Monso 2003 \{published data only\}

Monso E. Vaccination and antioxidant therapy [Vacunacion y tratamiento antioxidante]. Archivos de Bronconeumologia 2003;39(Suppl 3):31-3.

Nichol 1999 \{published data only\}

Nichol KL, Baken L, Wuorenma J, Nelson A. The health and economic benefits associated with pneumococcal vaccination of elderly persons with chronic lung disease. Archives of Internal Medicine 1999;159(20):2437-42.

Orcel 1994 \{published data only\}

Orcel B, Delclaux B, Baud M, Derenne JP. Oral immunization with bacterial extracts for protection against acute bronchitis in elderly institutionalized patients with chronic bronchitis. European Respiratory Journal 1994;7(3): $446-52$.

Ortqvist 1998 \{published data only\}

Ortqvist A, Hedlund J, Burman LA, Elbel E, Hofer $M$, Leinonen $M$, et al.Randomised trial of 23-valent pneumococcal capsular polysaccharide vaccine in prevention of pneumonia in middle-aged and elderly people. Swedish Pneumococcal Vaccination Study Group. Lancet 1998;351 (9100):399-403.

Patrick 1981 \{published data only\}

Patrick KM, Woolley FR. A cost-benefit analysis of immunisation of pneumococcal pneumonia. JAMA 1981; 245:473-7.

Preheim 1978 \{published data only\}

Preheim L, Rytel M. Pneumococcal infection after vaccination. Lancet 1978; Vol. 2:1317.

Riley 1977 \{published data only\}

Riley RD, Tarr PI, Andrews M. Immunisation with a polyvalent pneumococcal vaccine: reduction of adult respiratory mortality in a New Guinea Highlands community. Lancet 1977;1:1338-41.

Rochemaure 1988 \{published data only\}

Rochemaure J, Lehert Ph, Sauvaget J, Robillard M, Betbeder-Matibet A. Reduction with an immunomodulator of the infection rate in chronic bronchitis [Reduction par un immunomodulateur de taux d'infections respiratoires dans la bronchite chronique]. Revue de Pneumologie Clinique 1988;44(1):43-7.

Saag 1998 \{published data only\}

Saag KG, Doebbeling BN, Rohrer JE, Kolluri S, Peterson $\mathrm{R}$, Hermann ME, et al.Variation in tertiary prevention and health service utilization among the elderly. The role of urban-rural residence and supplemental insurance. Medical Care 1998;36(7):965-76.

Schwartz 1982 \{published data only\}

Schwartz JS. Pneumoncoccal vaccine: clinical efficacy and effectiveness. Annals of Internal Medicine 1982;96:208-20.

Shapiro 1984 \{published data only\}

Shapiro ED, Clemens JD. A controlled evaluation of the protective efficacy of pneumococcal vaccine for patients at high risk of serious pneumococcal infections. Annals of

Internal Medicine 1984;101:325-30.

Shapiro 1987 \{published data only\}

Shapiro ED. Pneumococcal vaccine failure. New England Journal of Medicine 1987;316(20):1272-3.

Shapiro 1991 \{published data only\}

Shapiro ED, Berg AT, Austrian R, Schroeder D, Parcells $\mathrm{V}$, Margollis A, et al.The protective efficacy of polyvalent pneumococcal polysaccharide vaccine. New England Journal of Medicine 1991;323:1453-60.

Sheikh 1999 \{published data only\}

Sheikh A. Evidence-based problem solving. What is the efficacy of pneumococcal vaccination in people with asthma?. Asthma in General Practice 1999;7(2):21-2.

Simberkoff 1986 \{published data only\}

Simberkoff MS, Cross AP, Al-Ibrahim M, Baltch AL, Geiseler PJ, Nadler J, et al.Efficacy of pneumococcal vaccine in high risk-patients. Results of a Veterans Administration Cooperative Study. New England Journal of Medicine 1986; 315(21):1318-27.

Simberkoff 1993 \{published data only\}

Simberkoff MS. Pneumococcal vaccine in the prevention of community-acquired pneumonia: a skeptical view of costeffectiveness. Seminars in Respiratory Infections 1993;8(4): 294-9.

Sims 1988 \{published data only\} Sims RV, Steinmann WC, McConville JH, King LR, Zwick WC, Schwartz JS. The clinical effectiveness of pneumococcal vaccine in the elderly. Annals of Internal Medicine 1988;108(5):653-7.

Sisk 1986 \{published data only\}

Sisk JE, Riegelman RK. Cost effectiveness of vaccination against pneumococcal pneumonia: an update. Annals of Internal Medicine 1986;104:79-86.

Smit 1977 \{published data only\} Smit P, Oberholzer D, Hayden-Smith S, Koornhof HJ, Hilleman MR. Protective efficacy of pneumoncoccal polysaccharide vaccines. JAMA 1977;238:2613-6.

van Ampting 1998 \{published data only\} van Amptin JMA, Bouter KP, Diepersloot RJA, Overbeek BP, Netten P, Erkelens DW. Pneumococcal bacteraemia: incidence, outcome and predisposing factors. European Journal of Internal Medicine 1998;9:145-50.

Wencker 1999 \{published data only\} Wencker M, Konietzko N. Alpha-1-protease inhibitor deficiency and pulmonary emphysema as viewed by pulmonary specialists in private practice [Alpha-1Proeinaseninhibitor-Mangel und Lungenemphysem aus der Sicht des niedergelassenen Pneumologen]. Atemwegs-und Lungenkrankheiten 1999;25(2):89-95.

Wenzel 1976 \{published data only\}

* Wenzel P, Craven R, Davies J, Hendley J, Hamory B, Gwaltney J. Field trial of an inactivated mycoplasma pneumoniae vaccine. Journal of Infectious Diseases 1976;134 (6):571-6. 
Wiebel 1977 \{published data only\}

Wiebel RE, Vella PP, McLean AA. Studies in human subjects of polyvalent pneucoccal vaccines. Proceedings of the Society for Experimental Biology and Medicine 1977;156:144-50.

Willems 1980 \{published data only\} Willems JS, Sanders CR, Riddiough MA. Cost effectiveness of vaccination against pneumococcal pneumonia. New England Journal of Medicine 1980;303:553-9.

Williams 1986 \{published data only\}

Williams JH, Moser KM. Pneumococcal vaccine and patients with chronic lung disease. Annals of Internal Medicine 1986;104(1):106-9.

Wright 1914 \{published data only\}

Wright AE, Morgan WP, Colebrook L, Dodgson RW. Prophylactic inoculation against pneumococcus infections. Lancet 1914:87-95.

\section{Additional references}

\section{ATS 1995}

American Thoracic Society. Standards for the diagnosis and care of patients with chronic obstructive pulmonary disease. American Journal of Respiratory and Critical Care Medicine 1995;152(5 Pt 2):S77-S121.

\section{ATS 2004}

American Thoracic Society. Management of stable COPD: pharmacological therapy. http://www.thoracic.org/COPD/ 6/other_agents.asp (accessed February 2005).

\section{Balter 1994}

Balter MS, et al.Recommendations on the management of chronic bronchitis. CMAJ 1994;151:5-23.

BTS 1997

COPD Guidelines Group of the Standards of Care Committee of the BTS. BTS Guidelines for the management of chronic obstructive pulmonary disease. Thorax 1997;52: S7-S15.

\section{Chapman 1991}

Chapman KR. Therapeutic algorithm for chronic obstructive pulmonary disease. The American Journal of Medicine 1991;91:17S-23S.
McKenzie 2003

McKenzie DK, Frith PA, Burdon JG, Town GI. The COPDX Plan: Australian and New Zealand guidelines for the management of chronic obstructive pulmonary disease. Medical Journal of Australia 2003;178(Suppl):7S-39S.

\section{Moher 1996}

Moher D, Jadad AR, Tugwell P. Assessing the quality of randomized controlled trials:current issues and future directions. International Journal of Technology Assessment in Health Care 1996;12:195-208.

\section{NCCCC 2004}

National Collaborating Centre for Chronic Conditions. Chronic obstructive pulmonary disease. National clinical guideline on management of chronic obstructive pulmonary disease in adults in primary and secondary care. Thorax 2004;59(Suppl 1):1-232.

\section{NHLBI 2001}

National Heart Lung and Blood Institute. Global strategy for the diagnosis, management, and prevention of chronic obstructive pulmonary disease. Bethesda: National Heart, Lung and Blood Institute; 2001. NIH Publication No 2701: 1-100.

\section{NICE 2004}

National Institute of Clinical Excellence. COPD: National clinical guideline on managment of chronic obstructive pulmonary disease in adults in primary and secondary care. Thorax 2004;59(Suppl 1):181-272.

\section{Pauwels 2001}

Pauwels RA, Buist AS, Calverley PM, Jenkins CR, Hurd SS, GOLD Scientific Committee. Global strategy for the diagnosis, management, and prevention of chronic obstructive pulmonary disease. NHLBI/WHO global initiative for chronic obstructive lung disease (GOLD) workshop summary. American Journal of Respiratory and Critical Care Medicine 2001;163(5):1047-8.

* Indicates the major publication for the study 


\title{
CHARACTERISTICS OF STUDIES
}

\section{Characteristics of included studies [ordered by study ID]}

\author{
Alfageme 2006
}

Methods

Setting of study: Population-based intervention

Study design: RCT parallel

Jadad scoring system:

-Described as randomized? Yes

-Described as double blind? No

-Described withdrawals/dropouts? Yes

-Randomization described, appropriate? Yes

-Blinding described, / appropriate? No

-Random / blinding method inappropriate? No indication

Total Score $=3$

Study outcomes assessed by person blinded to Tx allocation? Yes

Type of analysis: Case available

Participants

Total number of participants: 600 (4 lost to follow up; 2 from each group)

Gender distribution: vaccine group $M=96.6 \%$; control group $M=93.3 \%$

Mean age: vaccine group $=69$; control group $=68$ Age range: vaccine group $=62-73$; control group $=61$ 73

Inclusion criteria: COPD

Exclusion criteria: Prior pneumococcal vaccination, pregnant, immunosuppressed, known neoplasia, renal insufficiency in dialysis, HIV infection, hypogammaglobulinaemia, anatomical and/or functional asplenia Diagnostic criteria (COPD): SEPAR criteria (Sociedad Espanola de patologia respiratoria, or Spanish Society of Respiratory Pathology), FEV1< 80\% and FEV1/FVC $<70 \%$

Severity of COPD: vaccine group for FEV1 < 40\% = 132; >= 40\% = 166; control group for FEV1 $40 \%$

$=114 ;>=40 \%=184$

Current smokers: vaccine group $=22 \%$; control group $=26 \%$

Diagnostic criteria (pneumonia): Clinical symptoms (lower respiratory tract infection with fever) and imaging findings (new infiltrate typical of pneumonia which decreases during follow-up). Pneumococcal pneumonia diagnosed with isolated $S$ pneumoniae in blood, pleural fluid or bronchial samples.

Microbiological diagnosis (pneumococcus): presence of pneumonia and the isolation of $S$ pneumoniae from sputum, bronchoaspirate, blood, pleural fluid, or CSF

Interventions Vaccine type: 23 valent pneumococcal capsular polysaccharide

Numbers in each group: Intervention $=298$; No intervention $=298$

Dose: $0.5 \mathrm{ml}$ Pneumo23, Sanofi-Pasteur MSD

Delivery: subcutaneous injection in deltoid muscle

Co-interventions: None

Comparison: No vaccine

Duration of study: vaccine group, median of 980 days (range 20-1454); control group, median of 978 days (range 21-1183)

Outcomes

Types of outcomes measured:

Acute exacerbations (Yes) $\mathrm{C}=9 ; \mathrm{I}=30$

Pneumonia (Yes) $\mathrm{C}=5 ; \mathrm{I}=11$

Days of disability (No) 
Number of hospital admissions (Yes, call causes) C = 6; I = 18

Change in lung function (Reported, but cannot use data)

All cause mortality in yr post vac. (No)

Adverse effects of treatment (No)

Cost of vaccination (No)

Notes

Risk of bias

$\begin{array}{lll}\text { Item Authors' judgement } \quad \text { Description } & \end{array}$

Allocation concealment? Unclear Information not available

\section{Davis 1987}

Methods $\quad$ Randomised, double-blind, placebo controlled trial.

Method of randomisation: Random number table. participants studied for 1-48 months of treatment

Jadad scoring system:

-Described as randomized? Yes

-Described as double blind? Yes

-Described withdrawals/dropouts? No

-Randomization described, appropriate? Yes

-Blinding described, / appropriate? Yes

-Random / blinding method inappropriate? No

Total Score $=4$

Study outcomes assessed by person blinded to Tx allocation? Yes

Participants Total number of participants: 103

Gender distribution: Not stated

Mean age: Intervention $64 \pm 10$ Control $61 \pm 10$

Age range: Not stated

Inclusion criteria: COPD (assessed by clinical and pulmonary function criteria)

Exclusion criteria:

1. reversible airflow obstruction in the absence of chronic bronchitis (cough 3 of 12 months, and for 3 consecutive years) or emphysema as judged clinically, radiologically, and by lung function testing.

2. malignant neoplasms

3. sickle cell disease

4.severe renal impairment

5.severe hepatic impairment

Diagnostic criteria (COPD):ATS standards

Severity of COPD: Active: FEV1 $(\mathrm{L})=1.33 \pm 0.61$; FEV1/FVC=52 \pm 13 Placebo: FEV1 $(\mathrm{L})=1.47 \pm 0.75$; $\mathrm{FEV} 1 / \mathrm{FVC}=55 \pm 14$

Smoking Status: Active: current $=53 \%$, never $n=5$; Placebo: current $=33 \%$, never $n=5$

Diagnostic criteria (pneumonia): Clinical and imaging findings in the presence of pneumococcus in sputum

Etiological diagnosis (pneumococcus): Diagnosis only if pathogens isolated from blood or body fluids.

Processed $<6 \mathrm{hr}$ after collection. 
Davis 1987 (Continued)

Microbiological methods described.

Baseline characteristics (smokking status):

Current smokers: PLA: 27/53; VAX: $17 / 50$ ( $\mathrm{p}=0.036$ for difference); Non-smokers: PLA: 5; VAX: 5

Interventions $\quad$ Vaccine type: 14 pneumococcal capsular polysaccharide antigens

Numbers in each group: Intervention $=50$ Placebo $=53$

Dose: $0.5 \mathrm{ml}$ (50 mcg of each of the 14 capsular antigens)

Delivery: Subcutaneous injection

Co-interventions: None

Comparison: Saline

Duration of study: 24-32 months

Patients followed up for 48 months (mean follow up in each arm: PLA: 32.2 months; VAX: 31.7 months)

Outcomes

Anitbody titers; flora of sputum; incidence of pneumonia; mortality

Acute exacerbations (Yes)

Days of disability (No)

Number of hospital admissions (No)

Change in lung function (No)

All cause mortality in yr post vac. (Yes)

Adverse effects of treatment (No)

Cost of vaccination (No)

Comments on outcomes: Mortality cases from 1-48 months after vaccine

The rate of episodes $/ 1000$ patient years for prior pneumonia: Active $=35$, Placebo $=57$

The rate of episodes $/ 1000$ patient years for prior pneumococcal pneumonia: Active $=13.8$, Placebo $=22$.

9

Notes

Risk of bias

\begin{tabular}{l|l|l}
\hline Item & Authors' judgement & Description \\
\hline Allocation concealment? & Unclear & Information not available \\
\hline
\end{tabular}


Methods

Randomised, double-blind, placebo controlled trial. Method of randomisation: Not reported. Patients stratified by age and FEV1. Setting: Montreal Chest Hospital (stable ambulatory population). Withdrawals: 23 participants could not be traced for follow-up and were excluded from analysis of death rates Jadad scoring system:

-Described as randomized? Yes

-Described as double blind? Yes

-Described withdrawals/dropouts? No

-Randomization described, appropriate? No

-Blinding described, / appropriate? Yes

-Random / blinding method inappropriate?

Total Score $=3$

Type of analysis: Case available

Participants Total number of participants: 189

Gender distribution: Vaccine $(\mathrm{M})=66$ Placebo $(\mathrm{M})=69$

Mean age of patients: Vaccine $=66 \pm 9$ Placebo $=67 \pm 9$

Age range: 40-89

Inclusion criteria for active group: Patients seen in the outpatient clinic who had COPD (FEV1<1.5L)

Exclusion criteria:Previous pneumococcal vaccination, asthma, cystic fibrosis or bronchiectasis

Diagnostic criteria (COPD): Not stated, other than a prior diagnosis of COPD by their own physician Severity of COPD: Vaccine group (mean) FEV1=0.94L FVC=2.18L/s; Placebo group (mean) FEV1=0. 96L FVC $=2.13 \mathrm{~L} / \mathrm{s}$

Diagnostic criteria (pneumococcal pneumonia): Pneumonia defined as patient having symptoms of lower respiratory tract infection (fever, increased cough, and a change in colour or an increase in the quantity of sputum) and evidence of new infiltrate on chest X-ray.

Microbiological diagnosis (pneumococcus): Not stated, though sputum cultured in 10\% of subjects

$\mathrm{N}=$ 189. (VAX: 92; PLA: 97). Gender: PLA: M: 69; VAX: 66; Mean age: PLA: 67 (SD 9); VAX: 66 (SD 9); FEV1 (L): PLA: 0.96 (SD 0.30); VAX: 0.94 (SD 0.26); FVC: PLA: 2.13 (SD 0.64); VAX: 2.18 (SD $0.58)$

Interventions

Vaccine types: 14 valent pneumococcal polysaccharide (in one arm) and influenza vaccination (in the other arm)

Numbers in each group: Intervention $=92$ Placebo $=97$

Dose: not stated

Delivery: Injection

Co-interventions: none

Comparison: Saline (in one arm) and influenza vaccination (in the other arm)

Follow-up points: 6-month intervals

Duration of study: 2 years

Influenza vaccination (given at baseline, end of years 1 and $2 \ldots$ unless previous adverse reaction or declined)

Outcomes

Incidence of pneumonia; mortality (all cause); admission to hospital (all cause); length of hospital stay; Emergency visits (all causes); adverse events (pneumococcal sepsis)

Notes

Risk of bias
Item
Authors' judgement
Description

Injectable vaccines for preventing pneumococcal infection in patients with chronic obstructive pulmonary disease (Review) 
Leech 1987 (Continued)

\begin{tabular}{l|l} 
Allocation concealment? Unclear & Information not available
\end{tabular}

Steentoft 2006

Methods

Setting of study:

Hospital-based

Study design:

RCT parallel: 1 control group with three levels of steroid load, block randomized to vaccine or no vaccine Allocation concealment:

A (clear)

Jadad scoring system:

Described as randomized? Yes

Described as double blind? No

Described withdrawals/dropouts? No

Randomization described, appropriate? Yes

Blinding described, / appropriate? No

Random / blinding method inappropriate? No

Total Score $=2$

Study outcomes assessed by person blinded to Tx allocation?

Not stated for clinical diagnoses. Laboratory staff assessing antibody levels were blinded to allocation

Type of analysis:

Case available

Participants

Total number of participants:

49

Gender distribution:

$\mathrm{M}=27 ; \mathrm{F}=22$

Mean age:

Control: 67.5 years

Intervention: 65, 72 and 71 years for the three groups

Age range:

47-86 years

Inclusion criteria:

COPD

Exclusion criteria:

Prior pneumococcal vaccine (implied)

Diagnostic criteria (COPD):

COPD defined by GOLD guidelines (FEV1/FVC $<70 \%$, FEV1 reversibility-test $<200 \mathrm{ml}$ )

Severity of COPD at baseline:

Control: FEV1\%=50.2

Intervention: $\mathrm{FEV} 1 \%=48.2,46.0$, and 44.2 for the three groups

Smoking Status:

Active: current $=46 \%$, past $=54 \%$

Placebo: current $=58 \%$, past $=42 \%$

Diagnostic criteria (pneumonia):

Radiologically verified, though no other criteria stated

Etiological diagnosis (pneumococcus):

Not described

Injectable vaccines for preventing pneumococcal infection in patients with chronic obstructive pulmonary disease (Review) 


\begin{tabular}{|c|c|c|}
\hline Interventions & \multicolumn{2}{|c|}{$\begin{array}{l}\text { Vaccine type: } \\
23 \text { polyvalent pneumococcal vaccine } \\
\text { Numbers in each group: } \\
\text { Intervention = } 37 \\
\text { Placebo = } 12 \\
\text { Dose: } \\
0.5 \mathrm{ml} \\
\text { Delivery: } \\
\text { Subcutaneous injection } \\
\text { Co-interventions: } \\
\text { Three groups with various exposure patterns to oral prednisolone } \\
\text { * no steroid } 3 \text { months before vaccination, then steroids for } 4 \text { weeks after vaccination } \\
\text { * chronic steroid treatment, before and after vaccination } \\
\text { * vaccination after } 4 \text { weeks with steroid treatment, then no steroids after vaccination. } \\
\text { Groups } 1 \text { and } 3 \text { above received } 37.5 \mathrm{mg} \text { starting dose of prednisolone, tapered to } 0 \text { during the respective } \\
\text { time frames } \\
\text { Comparison: } \\
\text { No vaccine } \\
\text { Duration of study: } \\
6 \text { months }\end{array}$} \\
\hline Outcomes & \multicolumn{2}{|c|}{$\begin{array}{l}\text { Types of outcomes measured: } \\
\text { Acute exacerbations (Yes) } \mathrm{C}=9 ; \mathrm{I}=30 \\
\text { Pneumonia (Yes) } \mathrm{C}=5 ; \mathrm{I}=11 \\
\text { Days of disability (No)C = } 6 ; \mathrm{I}=18 \\
\text { Number of hospital admissions (Yes, though reasons for admissions not given) } \\
\text { Change in lung function (Reported, but cannot use data) } \\
\text { All cause mortality in yr post vac. (No) } \\
\text { Adverse effects of treatment (No) } \\
\text { Cost of vaccination (No) }\end{array}$} \\
\hline \multicolumn{3}{|l|}{ Notes } \\
\hline \multicolumn{3}{|l|}{ Risk of bias } \\
\hline Item & Authors' judgement & Description \\
\hline Allocation concealment? & Yes & Third party randomisation \\
\hline
\end{tabular}

COPD: Chronic obstructive pulmonary disease; FEV1: Forced expiratory volume in 1 second; MSD: Merck Sharpe and Dohme; PLA: Placebo; Tx: Treatment; VAX: vaccination 
Characteristics of excluded studies [ordered by study ID]

\begin{tabular}{|c|c|}
\hline Study & Reason for exclusion \\
\hline Aboussouan 1996 & Review article \\
\hline Anonymous 1999 & Position paper \\
\hline Anonymous $1999 \mathrm{~b}$ & Review article \\
\hline Austrian 1976 & $\begin{array}{l}\text { Participants are unlikely to have had COPD, and certainly } \\
\text { no results are available for COPD persons. }\end{array}$ \\
\hline Austrian 1981 & Review article \\
\hline Austrian 1984 & Editorial \\
\hline Bacle 1997 & Review article \\
\hline Bentley 1981 & Review article \\
\hline Bolan 1986 & Comparison of serotypes \\
\hline Broome 1981 & Review article \\
\hline Butler 1992 & Retrospective analysis of vaccine efficacy \\
\hline Butler 1993 & Retrospective analysis of vaccine efficacy \\
\hline Chodosh 1991 & Review article \\
\hline Christenson 2001 & Prospective study (not RCT) \\
\hline Davis 1984 & Preliminary results of the paper published in 1987 \\
\hline Douglas 1979 & Review article \\
\hline Douglas 1984 & Study carried out in children 6-54 months \\
\hline Ekwurzel 1938 & $\begin{array}{l}\text { Excluded because of young patients, which are unlikely to have had COPD ("youthful group, } 80 \% \text { being under } \\
25 \text { years of age") }\end{array}$ \\
\hline Ewig 1999 & Review article \\
\hline Farr 1995 & Matched case-controlled study \\
\hline Fedson 1989 & Review article \\
\hline Fedson 1994 & Review article \\
\hline
\end{tabular}


(Continued)

\begin{tabular}{|c|c|}
\hline Fedson 1999 & Review article \\
\hline Felton 1938 & Cohort observation study \\
\hline Ferguson 1993 & Review article \\
\hline Filice 1990 & Review article \\
\hline Fine 1994 & Meta-analysis \\
\hline Forrester 1987 & Case control study \\
\hline Foschino 1995 & Oral immunomodulator (not injectable vaccine) \\
\hline Gable 1990 & Retrospective cohort study \\
\hline Gaillat 1985 & No data were available for COPD patients \\
\hline Gardner 1993 & Review article \\
\hline Hak 1998 & Prospective cohort study \\
\hline Halasa 2001 & Injectable vaccine includes antigen from pneumococcus and other bacteria (in Polish language) \\
\hline Hilleman 1981 & Review article \\
\hline Hirschmann 1981 & Review article \\
\hline Hirschmann 1994 & Commentary \\
\hline Horwood 2002 & Review \\
\hline Jackson 2003 & Retrospective cohort study \\
\hline
\end{tabular}

Jonsson 2002 This is not a placebo controlled RCT. The trial compares a 23 valent pneumococcal vaccine with a type 6B polysaccharide conjugated to tetanus toxoid

Kaiser $1974 \quad$ Retrospective analysis of isolates

Kaufman 1941 Participants not adequately randomised. Participants allocated to active treatment by volunteering in one year and by alternate allocation in the subsequent year

Kaufman 1947 Likely to have included COPD participants given the age range of those involved in the study $(80 \%>60$ years), though inclusion of persons with COPD was not explicitly stated. Contact has been made with the originating institutions to obtain relevant analyses of this subgroup, though it is improbable that any results will be available due to the age of the publication

Klastersky $1986 \quad$ No data were available for COPD patients

Injectable vaccines for preventing pneumococcal infection in patients with chronic obstructive pulmonary disease (Review) 
(Continued)

\begin{tabular}{|c|c|}
\hline Klein 1983 & Trial of immunization rates \\
\hline Koivula 1997 & No data were available for COPD patients \\
\hline Kraus 1985 & Study of antibody responses \\
\hline LaForce 1989 & Review article \\
\hline Landesman 1983 & Study of antibody responses \\
\hline Larsson 1998 & Review article \\
\hline Leophonte 2001 & Review article \\
\hline MacLeod 1945 & CCT in young adults; COPD unlikely \\
\hline Madison 1998 & Review article \\
\hline Monso 2003 & Commentary \\
\hline Nichol 1999 & Retrospective cohort control study \\
\hline Orcel 1994 & Oral immunomodulator (not injectable vaccine) \\
\hline Ortqvist 1998 & No data were available for COPD patients \\
\hline Patrick 1981 & Cost benefit analysis \\
\hline Preheim 1978 & Case report \\
\hline Riley 1977 & No data were available for the chronic pulmonary disease patients \\
\hline Rochemaure 1988 & $\begin{array}{l}\text { The antigens for this oral immunomodulator are taken from Klebsiella pneumoniae and Escherichia coli (not } \\
\text { Streptococcus pneumoniae) }\end{array}$ \\
\hline Saag 1998 & Survey \\
\hline Schwartz 1982 & Review article \\
\hline Shapiro 1984 & Case-controlled study \\
\hline Shapiro 1987 & Correspondence \\
\hline Shapiro 1991 & Case control study \\
\hline Sheikh 1999 & Asthma study \\
\hline
\end{tabular}


(Continued)

\begin{tabular}{|c|c|}
\hline Simberkoff 1986 & No data were available for COPD patients \\
\hline Simberkoff 1993 & Review article \\
\hline Sims 1988 & Case-controlled study \\
\hline Sisk 1986 & Cost-benefit analysis, no data on efficacy \\
\hline Smit 1977 & $\begin{array}{l}\text { Participants are young adult novice miners, with no indication of chronic lung disease. Wrote to authors for } \\
\text { further information, but received no response as of Oct } 2004\end{array}$ \\
\hline van Ampting 1998 & Retrospective study of patients hospitalised with infection \\
\hline Wencker 1999 & Alpha 1 antitrypsin deficiency \\
\hline Wenzel 1976 & Inappropriate intervention using mycoplasma rather than streptococcus pneumoniae \\
\hline Wiebel 1977 & Antibody response study \\
\hline Willems 1980 & Non-randomised cost-effectiveness study \\
\hline Williams 1986 & Review article \\
\hline Wright 1914 & Participants are young (otherwise healthy) mining labourers without any indication of having COPD \\
\hline
\end{tabular}

COPD: Chronic obstructive pulmonary disease; CCT: case controlled trial; RCT: randomised controlled trial 
DATA ANDANALYSES

Comparison 1. Pneumococcal vaccine versus control

\begin{tabular}{|c|c|c|c|c|}
\hline Outcome or subgroup title & $\begin{array}{l}\text { No. of } \\
\text { studies }\end{array}$ & $\begin{array}{c}\text { No. of } \\
\text { participants }\end{array}$ & Statistical method & Effect size \\
\hline 1 Acute exacerbations & 1 & & Odds Ratio (M-H, Fixed, 95\% CI) & Totals not selected \\
\hline 1.1 Vaccine $>14$ serotypes & 1 & & Odds Ratio (M-H, Fixed, 95\% CI) & Not estimable \\
\hline $\begin{array}{l}1.2 \text { Vaccine } 14 \text { or less } \\
\text { serotypes }\end{array}$ & 0 & & Odds Ratio (M-H, Fixed, 95\% CI) & Not estimable \\
\hline 2 Pneumonia & 3 & 748 & Odds Ratio (M-H, Fixed, 95\% CI) & $0.89[0.58,1.37]$ \\
\hline 2.1 Vaccine $>14$ serotypes & 2 & 645 & Odds Ratio (M-H, Fixed, 95\% CI) & $0.97[0.61,1.53]$ \\
\hline $\begin{array}{l}2.2 \text { Vaccine } 14 \text { or less } \\
\text { serotypes }\end{array}$ & 1 & 103 & Odds Ratio (M-H, Fixed, 95\% CI) & $0.42[0.10,1.72]$ \\
\hline $\begin{array}{l}3 \text { Pneumonia by lung function at } \\
\text { baseline }\end{array}$ & 1 & 596 & Odds Ratio (M-H, Fixed, 95\% CI) & $0.71[0.41,1.22]$ \\
\hline 3.1 FEV $1<40 \%$ expected & 1 & 246 & Odds Ratio (M-H, Fixed, 95\% CI) & $0.47[0.22,1.01]$ \\
\hline 3.2 FEV1>=40\% expected & 1 & 350 & Odds Ratio (M-H, Fixed, 95\% CI) & $1.12[0.50,2.49]$ \\
\hline $\begin{array}{l}4 \text { Hospital admissions } \\
\text { (exacerbation of COPD) }\end{array}$ & 1 & & Rate Ratio (Fixed, 95\% CI) & Totals not selected \\
\hline 4.1 Vaccine $>14$ serotypes & 0 & & Rate Ratio (Fixed, 95\% CI) & Not estimable \\
\hline $\begin{array}{l}4.2 \text { Vaccine } 14 \text { or less } \\
\text { serotypes }\end{array}$ & 1 & & Rate Ratio (Fixed, 95\% CI) & Not estimable \\
\hline $\begin{array}{l}5 \text { Patients admitted to hospital } \\
\text { (any cause) }\end{array}$ & 1 & & Odds Ratio (M-H, Fixed, 95\% CI) & Totals not selected \\
\hline 5.1 Vaccine $>14$ serotypes & 1 & & Odds Ratio (M-H, Fixed, 95\% CI) & Not estimable \\
\hline $\begin{array}{l}5.2 \text { Vaccine } 14 \text { or less } \\
\text { serotypes }\end{array}$ & 0 & & Odds Ratio (M-H, Fixed, 95\% CI) & Not estimable \\
\hline $\begin{array}{l}6 \text { Hospital admissions } \\
\text { (pneumonia) }\end{array}$ & 1 & & Rate Ratio (Fixed, 95\% CI) & Totals not selected \\
\hline 6.1 Vaccine $>14$ serotypes & 0 & & Rate Ratio (Fixed, 95\% CI) & Not estimable \\
\hline $\begin{array}{l}6.2 \text { Vaccine } 14 \text { or less } \\
\text { serotypes }\end{array}$ & 1 & & Rate Ratio (Fixed, 95\% CI) & Not estimable \\
\hline 7 Hospital admissions (all causes) & 1 & & Rate Ratio (Fixed, 95\% CI) & Totals not selected \\
\hline 7.1 Vaccine $>14$ serotypes & 0 & & Rate Ratio (Fixed, 95\% CI) & Not estimable \\
\hline $\begin{array}{l}7.2 \text { Vaccine } 14 \text { or less } \\
\text { serotypes }\end{array}$ & 1 & & Rate Ratio (Fixed, 95\% CI) & Not estimable \\
\hline $\begin{array}{l}8 \text { Emergency visits (upper } \\
\text { respiratory tract infection) }\end{array}$ & 1 & & Rate Ratio (Fixed, 95\% CI) & Totals not selected \\
\hline 8.1 Vaccine $>14$ serotypes & 0 & & Rate Ratio (Fixed, 95\% CI) & Not estimable \\
\hline $\begin{array}{l}8.2 \text { Vaccine } 14 \text { or less } \\
\text { serotypes }\end{array}$ & 1 & & Rate Ratio (Fixed, 95\% CI) & Not estimable \\
\hline 9 Emergency visits (pneumonia) & 1 & & Rate Ratio (Fixed, 95\% CI) & Totals not selected \\
\hline 9.1 Vaccine $>14$ serotypes & 0 & & Rate Ratio (Fixed, 95\% CI) & Not estimable \\
\hline $\begin{array}{l}9.2 \text { Vaccine } 14 \text { or less } \\
\text { serotypes }\end{array}$ & 1 & & Rate Ratio (Fixed, 95\% CI) & Not estimable \\
\hline $\begin{array}{l}10 \text { Emergency visits (lower } \\
\text { respiratory tract infection) }\end{array}$ & 1 & & Rate Ratio (Fixed, 95\% CI) & Totals not selected \\
\hline
\end{tabular}

Injectable vaccines for preventing pneumococcal infection in patients with chronic obstructive pulmonary disease (Review)

Copyright (c) 2009 The Cochrane Collaboration. Published by John Wiley \& Sons, Ltd. 
10.1 Vaccine $>14$ serotypes 0

10.2 Vaccine 14 or less

serotypes

11 Emergency visits (any cause)

11.1 Vaccine $>14$ serotypes

11.2 Vaccine 14 or less serotypes

12 Death from cardio-respiratory causes, 6-48 months post vaccine

12.1 Vaccine $>14$ serotypes

12.2 Vaccine 14 or less serotypes

13 Death from all causes, 6-48 months post vaccine

13.1 Vaccine $>14$ serotypes

13.2 Vaccine 14 or less serotypes
Rate Ratio (Fixed, 95\% CI)

Rate Ratio (Fixed, 95\% CI)

Rate Ratio (Fixed, 95\% CI)

Rate Ratio (Fixed, 95\% CI)

Rate Ratio (Fixed, 95\% CI)

888

Odds Ratio (M-H, Fixed, 95\% CI)

596

Odds Ratio (M-H, Fixed, 95\% CI)

Odds Ratio (M-H, Fixed, 95\% CI)

888 Odds Ratio (M-H, Fixed, 95\% CI)

596 Odds Ratio (M-H, Fixed, 95\% CI)

Odds Ratio (M-H, Fixed, 95\% CI)
Not estimable

Not estimable

Totals not selected

Not estimable

Not estimable

$1.07[0.69,1.66]$

$1.11[0.66,1.88]$

$0.98[0.44,2.18]$

$0.94[0.67,1.33]$

$0.98[0.65,1.47]$

$0.86[0.44,1.66]$

\section{Analysis I.I. Comparison I Pneumococcal vaccine versus control, Outcome I Acute exacerbations.}

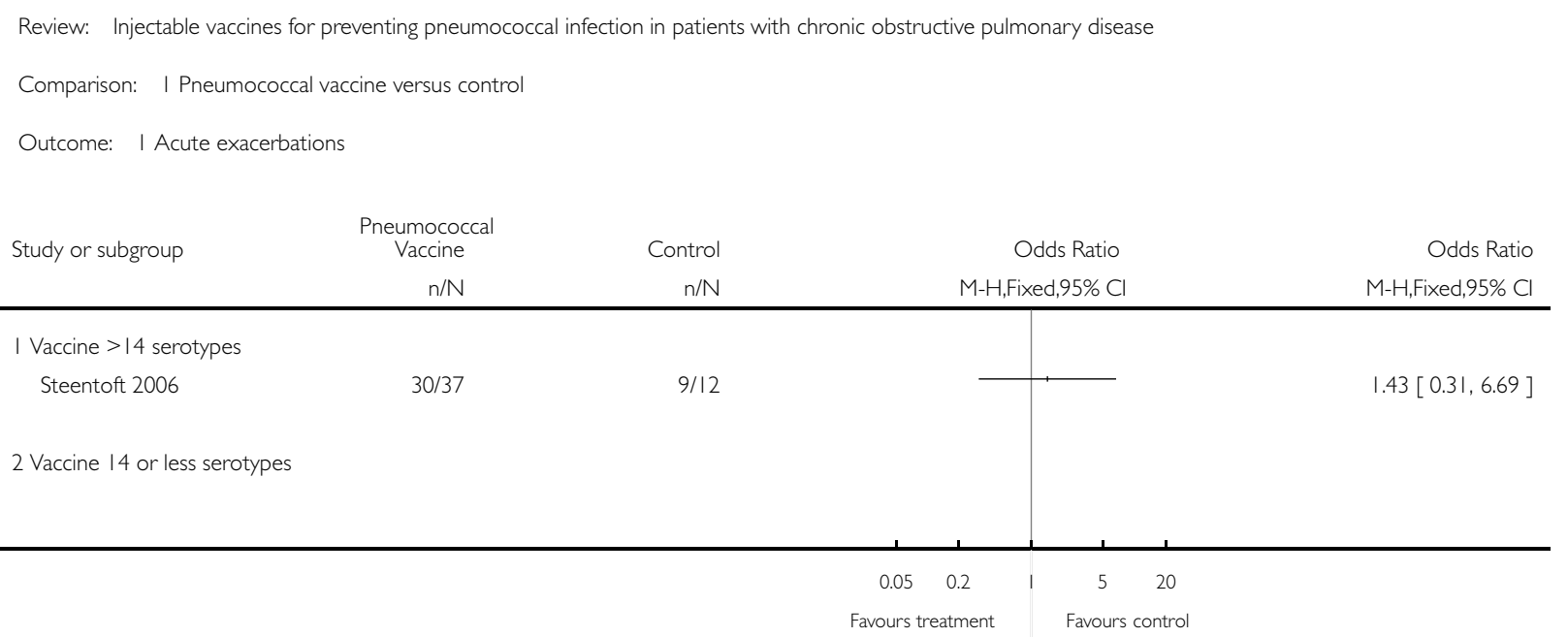




\section{Analysis I.2. Comparison I Pneumococcal vaccine versus control, Outcome 2 Pneumonia.}

Review: Injectable vaccines for preventing pneumococcal infection in patients with chronic obstructive pulmonary disease

Comparison: I Pneumococcal vaccine versus control

Outcome: 2 Pneumonia

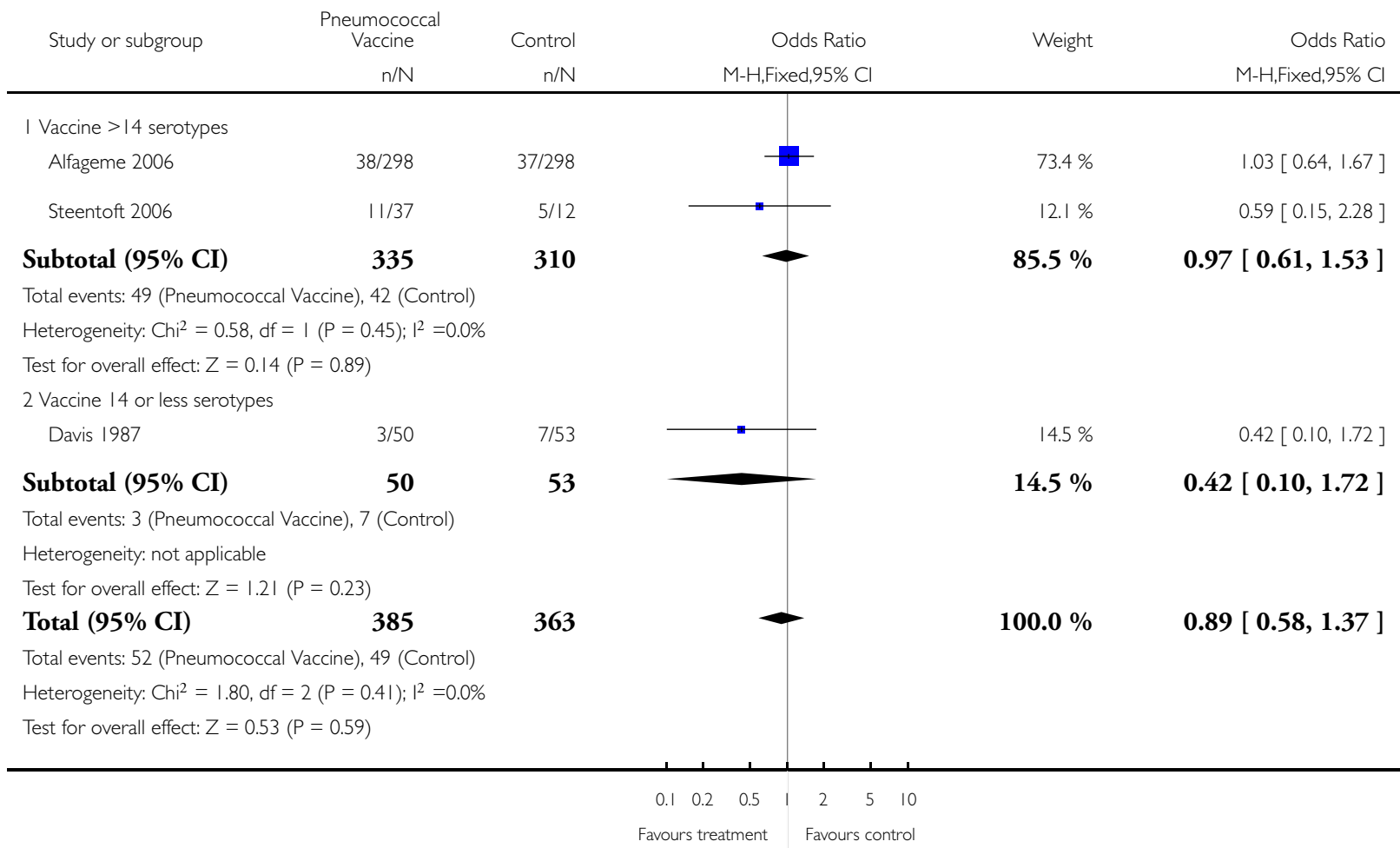


Analysis I.3. Comparison I Pneumococcal vaccine versus control, Outcome 3 Pneumonia by lung function at baseline.

Review: Injectable vaccines for preventing pneumococcal infection in patients with chronic obstructive pulmonary disease

Comparison: I Pneumococcal vaccine versus control

Outcome: 3 Pneumonia by lung function at baseline

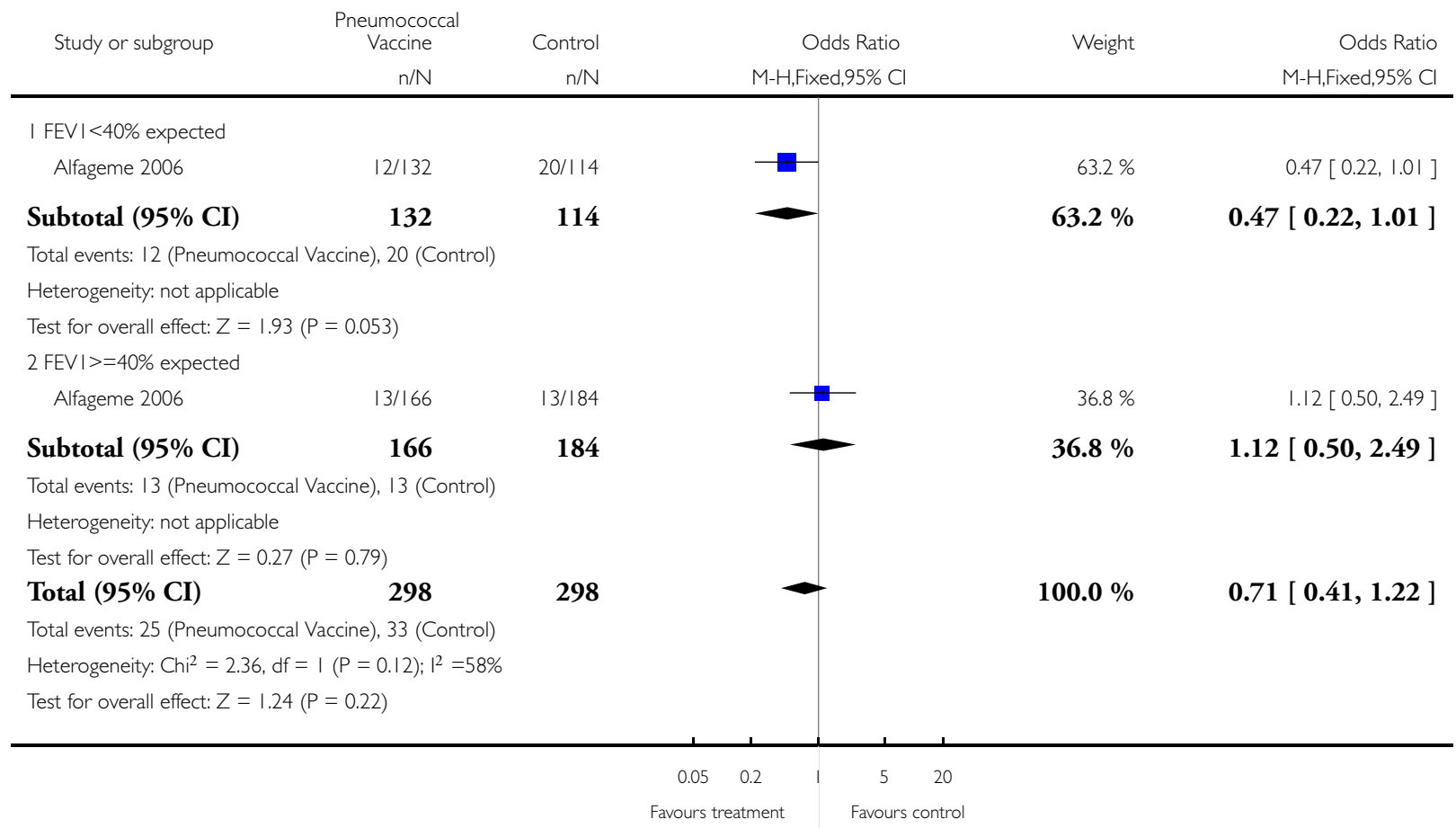


Analysis I.4. Comparison I Pneumococcal vaccine versus control, Outcome 4 Hospital admissions (exacerbation of COPD).

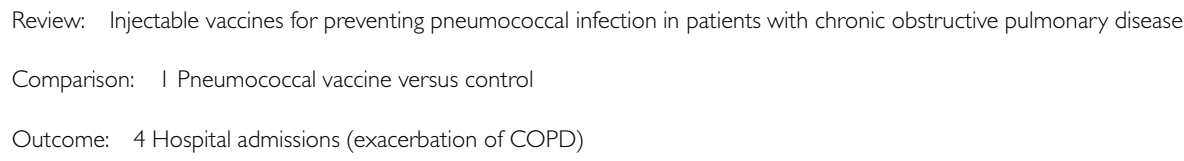

Analysis I.5. Comparison I Pneumococcal vaccine versus control, Outcome 5 Patients admitted to hospital (any cause).

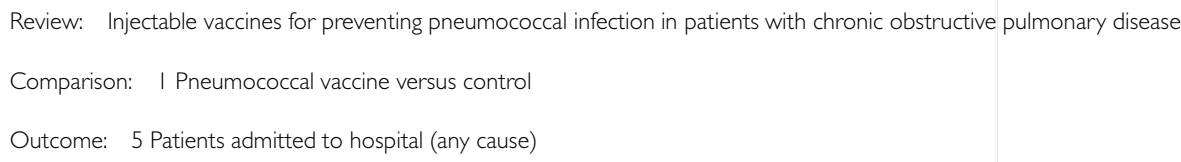

\begin{tabular}{|c|c|c|c|c|}
\hline Study or subgroup & $\begin{array}{c}\text { Pneumococcal } \\
\text { Vaccine }\end{array}$ & Control & Odds Ratio & Odds Ratio \\
\hline & $\mathrm{n} / \mathrm{N}$ & $\mathrm{n} / \mathrm{N}$ & M-H,Fixed,95\% Cl & M-H,Fixed,95\% Cl \\
\hline
\end{tabular}

I Vaccine $>14$ serotypes

Steentoft 2006 $\mathrm{M}-\mathrm{H}, \mathrm{Fixed}, 95 \% \mathrm{Cl}$

2 Vaccine 14 or less serotypes

$\begin{array}{lllllll}0.1 & 0.2 & 0.5 & 1 & 2 & 5 & 10\end{array}$

Favours treatment Favours control 
Analysis I.6. Comparison I Pneumococcal vaccine versus control, Outcome 6 Hospital admissions (pneumonia).

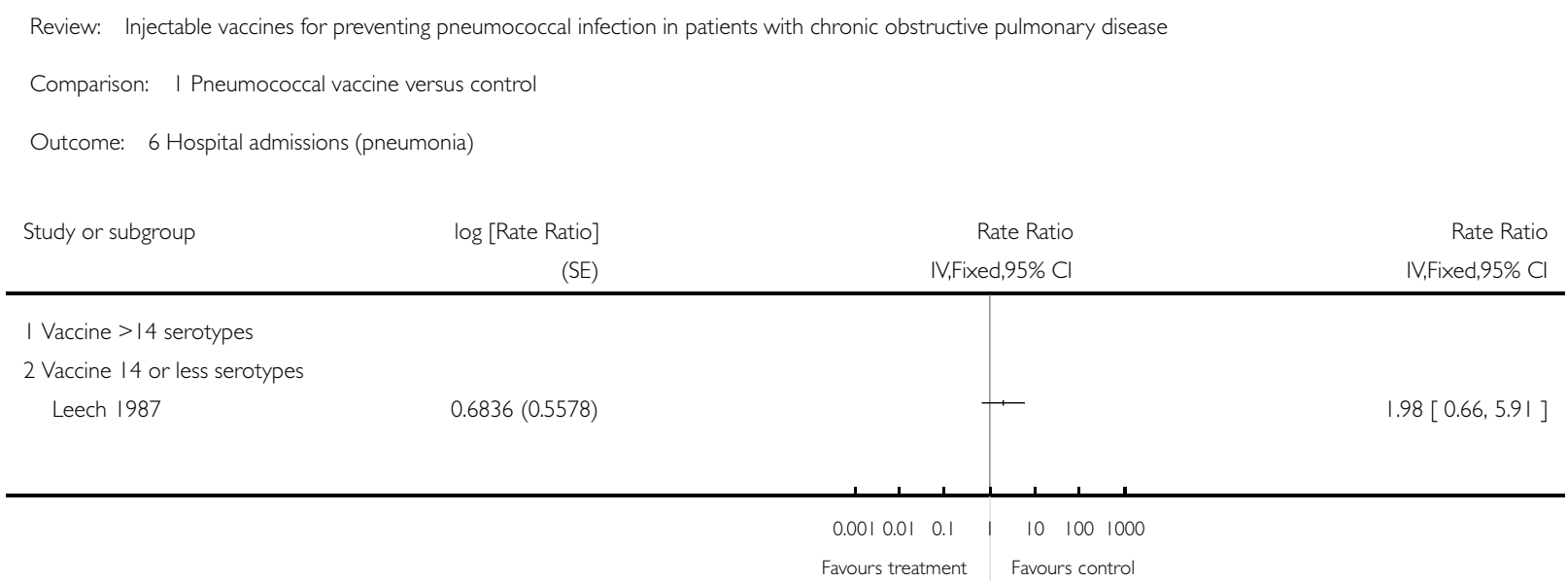

Analysis I.7. Comparison I Pneumococcal vaccine versus control, Outcome 7 Hospital admissions (all causes).

Review: Injectable vaccines for preventing pneumococcal infection in patients with chronic obstructive pulmonary disease

Comparison: I Pneumococcal vaccine versus control

Outcome: 7 Hospital admissions (all causes)

Study or subgroup $\quad \log$ [Rate Ratio] Rate Ratio Ratio

(SE) IV,Fixed,95\% Cl IV,Fixed,95\% Cl

I Vaccine $>14$ serotypes

2 Vaccine 14 or less serotypes

Leech 1987

$0.0088(0.1704)$

$1.01[0.72,1.41]$ 
Analysis I.8. Comparison I Pneumococcal vaccine versus control, Outcome 8 Emergency visits (upper respiratory tract infection).

\begin{tabular}{|c|c|c|c|}
\hline \multicolumn{4}{|c|}{ Comparison: I Pneumococcal vaccine versus control } \\
\hline \multicolumn{4}{|c|}{ Outcome: 8 Emergency visits (upper respiratory tract infection) } \\
\hline \multirow[t]{2}{*}{ Study or subgroup } & $\log$ [Rate Ratio] & Rate Ratio & Rate Ratio \\
\hline & (SE) & IV,Fixed,95\% Cl & IV,Fixed,95\% Cl \\
\hline \multicolumn{4}{|c|}{ I Vaccine $>14$ serotypes } \\
\hline \multicolumn{4}{|c|}{2 Vaccine 14 or less serotypes } \\
\hline Leech 1987 & $0.258(0.33)$ & + & $1.29[0.68,2.47]$ \\
\hline
\end{tabular}

Analysis I.9. Comparison I Pneumococcal vaccine versus control, Outcome 9 Emergency visits (pneumonia).

Review: Injectable vaccines for preventing pneumococcal infection in patients with chronic obstructive pulmonary disease

Comparison: I Pneumococcal vaccine versus control

Outcome: 9 Emergency visits (pneumonia)

Study or subgroup $\quad \log$ [Rate Ratio] Rate Ratio Ratio

(SE) IV,Fixed,95\% Cl IV,Fixed,95\% Cl

I Vaccine $>14$ serotypes

2 Vaccine 14 or less serotypes

Leech 1987 
Analysis I.10. Comparison I Pneumococcal vaccine versus control, Outcome 10 Emergency visits (lower respiratory tract infection).
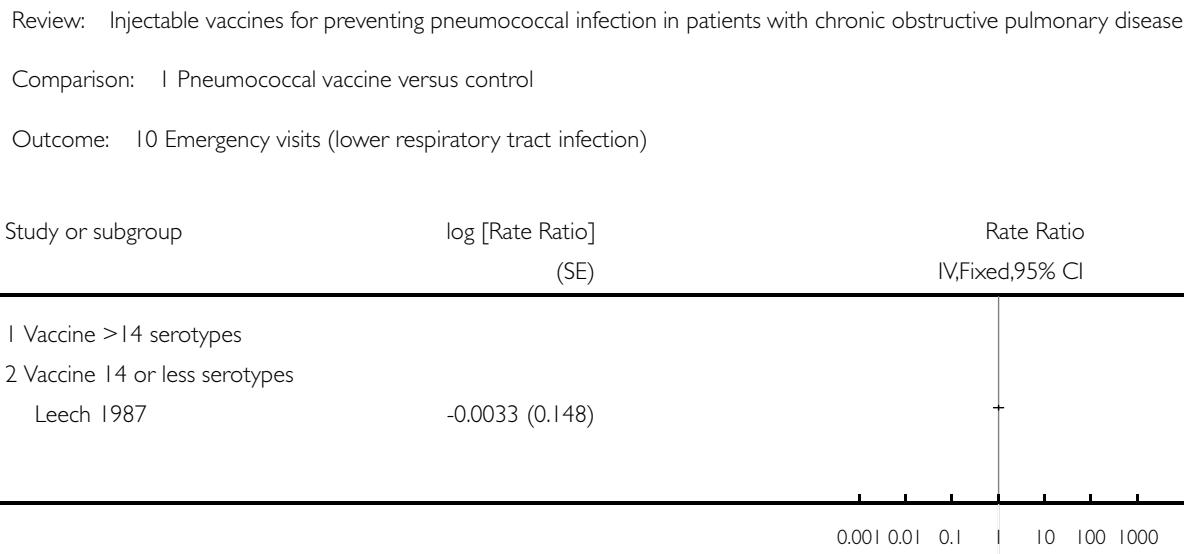

Favours treatment Favours control

\section{Analysis I.I I. Comparison I Pneumococcal vaccine versus control, Outcome I I Emergency visits (any} cause).

Review: Injectable vaccines for preventing pneumococcal infection in patients with chronic obstructive pulmonary disease

Comparison: | Pneumococcal vaccine versus control

Outcome: II Emergency visits (any cause)

Study or subgroup $\quad \log$ [Rate Ratio] Rate Ratio Ratio

I Vaccine $>14$ serotypes

2 Vaccine 14 or less serotypes

Leech 1987 
Analysis I.I2. Comparison I Pneumococcal vaccine versus control, Outcome I2 Death from cardiorespiratory causes, 6-48 months post vaccine.

\begin{tabular}{|c|c|c|c|c|c|}
\hline \multicolumn{6}{|c|}{ Comparison: I Pneumococcal vaccine versus control } \\
\hline \multicolumn{6}{|c|}{ Outcome: 12 Death from cardio-respiratory causes, 6-48 months post vaccine } \\
\hline \multirow[t]{2}{*}{ Study or subgroup } & $\begin{array}{l}\text { Pneumococca } \\
\text { Vaccine }\end{array}$ & Control & Odds Ratio & \multirow[t]{2}{*}{ Weight } & Odds Ratio \\
\hline & $\mathrm{n} / \mathrm{N}$ & $n / N$ & M-H,Fixed,95\% Cl & & M-H,Fixed,95\% Cl \\
\hline \multicolumn{6}{|l|}{ I Vaccine $>\mid 4$ serotypes } \\
\hline Alfageme 2006 & $33 / 298$ & $30 / 298$ & - & $68.7 \%$ & $1.11[0.66,1.88]$ \\
\hline Subtotal $(95 \% \mathrm{CI})$ & 298 & 298 & 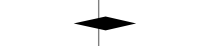 & $68.7 \%$ & $1.11[0.66,1.88]$ \\
\hline \multicolumn{6}{|c|}{ Total events: 33 (Pneumococcal Vaccine), 30 (Control) } \\
\hline \multicolumn{6}{|c|}{ Heterogeneity: not applicable } \\
\hline \multicolumn{6}{|c|}{ Test for overall effect: $Z=0.40(P=0.69)$} \\
\hline \multicolumn{6}{|c|}{2 Vaccine 14 or less serotypes } \\
\hline Davis 1987 & $8 / 50$ & $7 / 53$ & - & $14.7 \%$ & $1.25[0.42,3.75]$ \\
\hline Leech 1987 & $5 / 92$ & $7 / 97$ & & $16.6 \%$ & $0.74[0.23,2.42]$ \\
\hline Subtotal $(95 \% \mathrm{CI})$ & 142 & 150 & & $31.3 \%$ & $0.98[0.44,2.18]$ \\
\hline \multicolumn{6}{|c|}{ Total events: I3 (Pneumococcal Vaccine), 14 (Control) } \\
\hline \multicolumn{6}{|c|}{ Heterogeneity: $\mathrm{Ch}^{2}=0.41, \mathrm{df}=1(P=0.52) ; 1^{2}=0.0 \%$} \\
\hline \multicolumn{6}{|c|}{ Test for overall effect: $Z=0.05(P=0.96)$} \\
\hline Total $(95 \% \mathrm{CI})$ & 440 & 448 & - & $100.0 \%$ & $1.07[0.69,1.66]$ \\
\hline \multicolumn{6}{|c|}{ Total events: 46 (Pneumococcal Vaccine), 44 (Control) } \\
\hline \multicolumn{6}{|c|}{ Heterogeneity: $\mathrm{Ch}^{2}{ }^{2}=0.47, \mathrm{df}=2(\mathrm{P}=0.79) ; \mathrm{I}^{2}=0.0 \%$} \\
\hline Test for overall effect: $Z=$ & $=0.76)$ & & & & \\
\hline
\end{tabular}




\section{Analysis I.13. Comparison I Pneumococcal vaccine versus control, Outcome I3 Death from all causes, 6-} 48 months post vaccine.

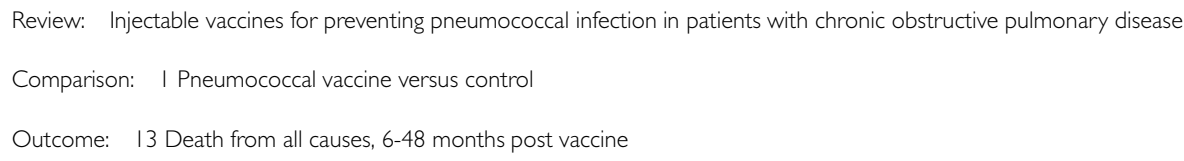

$\mathrm{n} / \mathrm{N}$

I Vaccine $>14$ serotypes

$$
\text { Alfageme } 2006
$$

Subtotal (95\% CI)

298

Total events: 57 (Pneumococcal Vaccine), 58 (Control)

Heterogeneity: not applicable

Test for overall effect: $Z=0.10(P=0.92)$

2 Vaccine 14 or less serotypes

$$
\begin{aligned}
& \text { Davis } 1987 \\
& \text { Leech } 1987
\end{aligned}
$$

Subtotal (95\% CI)

Total events: 20 (Pneumococcal Vaccine), 24 (Control) Heterogeneity: $\mathrm{Chi}^{2}=1.28, \mathrm{df}=\mathrm{I}(\mathrm{P}=0.26) ; \mathrm{I}^{2}=22 \%$

Test for overall effect: $Z=0.46(P=0.64)$

Total (95\% CI)

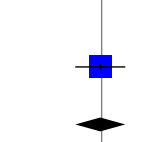

Total events: 77 (Pneumococcal Vaccine), 82 (Control) Heterogeneity: $\mathrm{Chi}^{2}=1.38, \mathrm{df}=2(\mathrm{P}=0.50) ; \mathrm{I}^{2}=0.0 \%$ Test for overall effect: $Z=0.33(P=0.74)$

$58 / 298$

298

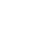

\section{WHAT'S NEW}

Last assessed as up-to-date: 20 July 2006.

\begin{tabular}{lll}
\hline Date & Event & Description \\
\hline 31 July 2008 & Amended & Converted to new review format. \\
\hline
\end{tabular}




\section{H I S T O R Y}

Protocol first published: Issue 1, 1999

Review first published: Issue 4, 2006

$\begin{array}{lll}\text { Date Event } & \text { Description }\end{array}$

21 July 2006 New citation required and conclusions have changed Substantive amendment

\section{CONTRIBUTIONSOFAUTHORS}

Cates:

review of protocol, editing

Lasserson:

technical support, electronic searches of Cochrane registers, data extraction

Poole:

development of protocol, selection of studies, data checking, editing

Wood-Baker:

development of protocol, selection of studies, data extraction, data entry, analysis, interpretation

Walters:

selection of studies, data extraction

Granger:

selection of studies, data extraction, data entry, analysis, interpretation, writing up of review

Mangtani:

selection of studies, data extraction

\section{DECLARATIONSOF INTEREST}

None known. 


\section{SOURCES OF SUPPORT}

\section{Internal sources}

- University of Tasmania, Australia.

\section{External sources}

- Commonwealth Department of Health and Ageing, Australia.

\section{INDEX TERMS}

\section{Medical Subject Headings (MeSH)}

Pneumococcal Infections [mortality; * prevention \& control]; Pneumococcal Vaccines [*administration \& dosage]; Pulmonary Disease, Chronic Obstructive [ ${ }^{*}$ complications; mortality]; Randomized Controlled Trials as Topic

\section{MeSH check words}

Humans; Middle Aged 